University of South Florida

DIGITAL COMMONS

Digital Commons @ University of

@ UNIVERSITY OF SOUTH FLORIDA

South Florida

2-2019

\title{
Improving Satellite Global Chlorophyll a Data Products Through Algorithm Refinement and Data Recovery
}

\author{
Chuanmin $\mathrm{Hu}$ \\ University of South Florida, huc@usf.edu \\ Lian Feng \\ University of South Florida \\ Zhongping Lee \\ University of Massachusetts Boston \\ Bryan A. Franz \\ NASA GSFC \\ Sean W. Bailey \\ NASA GSFC
}

See next page for additional authors

Follow this and additional works at: https://digitalcommons.usf.edu/msc_facpub

Part of the Life Sciences Commons

\section{Scholar Commons Citation}

Hu, Chuanmin; Feng, Lian; Lee, Zhongping; Franz, Bryan A.; Bailey, Sean W.; Werdell, Jeremy; and Proctor, Christopher W., "Improving Satellite Global Chlorophyll a Data Products Through Algorithm Refinement and Data Recovery" (2019). Marine Science Faculty Publications. 2005.

https://digitalcommons.usf.edu/msc_facpub/2005

This Article is brought to you for free and open access by the College of Marine Science at Digital Commons @ University of South Florida. It has been accepted for inclusion in Marine Science Faculty Publications by an authorized administrator of Digital Commons @ University of South Florida. For more information, please contact digitalcommons@usf.edu. 


\section{Authors}

Chuanmin Hu, Lian Feng, Zhongping Lee, Bryan A. Franz, Sean W. Bailey, Jeremy Werdell, and Christopher W. Proctor 


\section{JGR Oceans}

\author{
RESEARCH ARTICLE \\ 10.1029/2019JC014941 \\ Key Points: \\ - OCI chlorophyll $a$ algorithm \\ revisited for its algorithm \\ coefficients and transition \\ - New quality-control scheme \\ proposed to mask straylight \\ - Both data quality and data quantity \\ improved for global oceans
}

Correspondence to:

C. Hu,

huc@usf.edu

Citation:

Hu, C., Feng, L., Lee, Z., Franz, B. A., Bailey, S. W., Werdell, P. J., \& Proctor,

C. W. (2019). Improving satellite global chlorophyll $a$ data products through algorithm refinement and data recovery. Journal of Geophysical Research: Oceans, 124, 1524-1543. https://doi.org/10.1029/2019JC014941

Received 3 JAN 2019 Accepted 9 FEB 2019 Accepted article online 14 FEB 2019 Published online 7 MAR 2019

(C)2019. American Geophysical Union. All Rights Reserved.

\section{Improving Satellite Global Chlorophyll $a$ Data Products Through Algorithm Refinement and Data Recovery}

\author{
Chuanmin $\mathrm{Hu}^{1}$ (D), Lian Feng ${ }^{1}$, Zhongping Lee ${ }^{2}$ (D), Bryan A. Franz ${ }^{3}$ (D), Sean W. Bailey ${ }^{3}$, \\ P. Jeremy Werdell ${ }^{3}$ D , and Christopher W. Proctor ${ }^{3,4}$ iD \\ ${ }^{1}$ College of Marine Science, University of South Florida, St. Petersburg, FL, USA, ${ }^{2}$ School for the Environment, University \\ of Massachusetts Boston, Boston, MA, USA, ${ }^{3}$ NASA GSFC, Greenbelt, MD, USA, ${ }^{4}$ Science Systems and Applications, Inc., \\ Lanham, MD, USA
}

Abstract A recently developed algorithm to estimate surface ocean chlorophyll $a$ concentrations ( $\mathrm{Chl}$ in $\mathrm{m} \mathrm{m} \mathrm{m}^{-3}$ ), namely, the ocean color index (OCI) algorithm, has been adopted by the U.S. National Aeronautics and Space Administration to apply to all satellite ocean color sensors to produce global $\mathrm{Chl}$ maps. The algorithm is a hybrid between a band-difference color index algorithm for low-Chl waters and the traditional band-ratio algorithms (OCx) for higher-Chl waters. In this study, the $\mathrm{OCI}$ algorithm is revisited for its algorithm coefficients and for its algorithm transition between color index and $\mathrm{OCx}$ using a merged data set of high-performance liquid chromatography and fluorometric Chl. Results suggest that the new OCI algorithm (OCI2) leads to lower Chl estimates than the original OCI (OCI1) for $\mathrm{Chl}<0.05 \mathrm{mg} \mathrm{m}^{-3}$, but smoother algorithm transition for Chl between 0.25 and $0.40 \mathrm{mg} \mathrm{m}^{-3}$. Evaluation using in situ data suggests that similar to OCI1, OCI2 has significantly improved image quality and cross-sensor consistency between SeaWiFS, MODISA, and VIIRS over the OCx algorithms for oligotrophic oceans. Mean cross-sensor difference in monthly $\mathrm{Chl}$ data products over global oligotrophic oceans reduced from $\sim 10 \%$ for OCx to $1-2 \%$ for OCI2. More importantly, data statistics suggest that the current straylight masking scheme used to generate global Chl maps can be relaxed from $7 \times 5$ to $3 \times 3$ pixels without losing data quality in either Chl or spectral remote sensing reflectance $\left(\mathrm{R}_{\mathrm{rs}}(\lambda), \mathrm{sr}^{-1}\right)$ for not just oligotrophic oceans but also more productive waters. Such a relaxed masking scheme yields an average relative increase of $39 \%$ in data quantity for global oceans, thus making it possible to reduce data product uncertainties and fill data gaps.

Plain Language Summary There are generally two issues with any remote sensing data product: data quality (accuracy) and data quantity (coverage). In this work, these two issues for global ocean data products of chlorophyll $a$ concentrations ( $\mathrm{Chl} \mathrm{in} \mathrm{mg} \mathrm{m}^{-3}$ ) are investigated through revisiting a recently developed algorithm concept and statistical analyses of cloud-adjacent data. The use of more data in algorithm development leads to slightly different algorithm coefficients and smoother transition between clear and turbid waters, and a new straylight masking scheme is proposed to "recover" some of the previously masked data in the global data products. The new algorithm leads to significantly improved cross-sensor consistency (SeaWiFS, MODIS, VIIRS) as compared to the traditional band-ratio algorithms, with mean monthly difference reduced from $10 \%$ to $1-2 \%$. The new straylight masking scheme leads to relative increase of $39 \%$ in data quantity in the global ocean without losing data quality. These improvements are expected to reduce uncertainties and fill gaps in the global data products.

\section{Introduction}

One of the most historically meaningful and utilized data products from ocean color satellites is surface concentration of chlorophyll $a\left(\mathrm{Chl} \mathrm{in} \mathrm{mg} \mathrm{m}^{-3}\right)$ because this photosynthetic pigment plays a fundamental role in affecting ocean biology and ecology. To many researchers, $\mathrm{Chl}$ and "ocean color" have become synonymous, as Chl (plus accessary phaeopigment) has been the main data product since the proof-of-concept Coastal Zone Color Scanner (1978-1986) era. Indeed, all satellite ocean color missions have Chl as one of their main data products, for example, the SeaWiFS mission (Sea-viewing Wide Field-of-view Sensor; 1997-2010), MODIS (Moderate Resolution Imaging Spectroradiometer; 1999 to present on Terra and 2002 to present on Aqua), MERIS (Medium Resolution Spectroradiometer; 2002-2012), and the most recent VIIRS (Visible Infrared Imaging Radiometer Suite; 2012 to present). 
Deriving accurate $\mathrm{Chl}$ data products from measurements several hundreds of kilometers above the Earth requires a thorough understanding of the entire system of ocean color measurements from the satellite to the sea surface. This includes the development and implementation of algorithms for global routine processing such as on-orbit temporal stability corrections, vicarious calibration, atmospheric correction (including whitecap and Sun glint corrections), and bio-optical algorithm development. All steps except the last one are designed to obtain accurate spectral remote sensing reflectance in every spectral band $\left(\mathrm{R}_{\mathrm{rs}}(\lambda), \mathrm{sr}^{-1}\right)$, and the last one is to estimate $\mathrm{Chl}$ from $\mathrm{R}_{\mathrm{rs}}(\lambda)$. Descriptions of all steps above are beyond the scope of this paper as they can be found in the literature (e.g., SeaWiFS technical report series; Franz et al., 2007; Frouin et al., 1996; Gordon, 1997; Gordon \& Wang, 1994; McClain, 2009; McClain et al., 2004; Moore et al., 2015; Stumpf et al., 2003; Wang \& Bailey, 2001; Wang \& Shi, 2007). Instead, the focus of this paper is on a Chl algorithm optimized for global oceans (i.e., data quality) and also on data quantity through quality control.

A review of Chl algorithms for global oceans has been provided in recent papers including Dierssen (2010) and $\mathrm{Hu}$ and Campbell (2014). Briefly, there are two general approaches to estimate Chl from satellite-derived $\mathrm{R}_{\mathrm{rs}}(\lambda)$. The first is empirical, through regression of $\mathrm{R}_{\mathrm{rs}}(\lambda)$ band ratios or band differences against Chl (e.g., Hu et al., 2012; Kahru \& Mitchell, 1999; O'Reilly et al., 2000). The second is semianalytical, through solving Chl- $\mathrm{R}_{\mathrm{rs}}(\lambda)$ equations established from simplifications of radiative transfer theory using certain bio-optical assumptions (e.g., Carder et al., 1999; IOCCG, 2006; Lee et al., 2002; Maritorena et al., 2002; Sathyendranath et al., 1989). While in principle the latter should lead to more accurate results than the former because water constituents affecting $\mathrm{R}_{\mathrm{rs}}(\lambda)$ are explicitly separated, in practice both approaches have their own strengths and weaknesses. For example, the latter relies on tuning of the assignment of assumptions in the bio-optical relationships using global or local data sets. The former accounts for $\mathrm{R}_{\mathrm{rs}}(\lambda)$ input errors through tuning of the empirical coefficients, although the empirical design makes it impossible to differentiate explicitly the various in-water constituents. On the other hand, empirical approaches through either band ratio or band difference can partially compensate some of the $\mathrm{R}_{\mathrm{rs}}(\lambda)$ input errors because these errors to a large extent are spectrally related (Hu et al., 2013). Thus, following the tradition from the CZCS era, even though empirical Chl estimates are known to contain large uncertainties (Dierssen, 2010) and such uncertainties may vary across different ocean basins (Szeto et al., 2011), the U.S. National Aeronautics and Space Administration (NASA) still uses empirical algorithms to produce default (also called "standard") Chl products from the mainstream sensors.

Recently, NASA adapted a new Chl algorithm proposed by Hu et al. (2012) as the default global algorithm in their reprocessing 2014.0, with new processing codes updated in the software package SeaDAS (version 7.2). The new algorithm is a hybrid of a novel concept of three-band difference color index (CI) and the traditionally band ratio algorithm (OC4 or OC3, termed as OCx in this paper; O'Reilly et al., 2000) to apply to low-Chl waters $\left(\mathrm{Chl} \leq 0.25 \mathrm{mg} \mathrm{m}^{-3}\right)$ and higher-Chl waters $\left(\mathrm{Chl}>0.3 \mathrm{mg} \mathrm{m}^{-3}\right)$, respectively. For intermediate-Chl waters in the transition zone of $0.25-0.3 \mathrm{mg} \mathrm{m}^{-3}$, a weighted mixture of the two algorithms is used. Collectively, the algorithm is termed as Ocean Color Index (OCI) algorithm. Following this change, after independent evaluation of the new algorithm, the U.S. National Oceanic and Atmospheric Administration (NOAA) also made similar changes in their processing code to apply the new algorithm approach (after further tuning of algorithm coefficients) for VIIRS global processing (Wang \& Son, 2016). This is the first time since the CZCS era that the algorithm concept has been changed in global data processing from band ratio to band difference for low-Chl waters. Along with extensive evaluations by the community (e.g., Brewin et al., 2013, 2015) and by NASA, the reason behind these changes is mainly because of the tolerance of the CI design to known and unknown errors from atmospheric correction and other sources; such a tolerance leads to reductions in many image artifacts. For example, in addition to the documented error tolerance in $\mathrm{Hu}$ et al. (2012), NASA found that the CI algorithm was also tolerant to an unknown error of digital count round off in one of the atmospheric correction bands due to sensor degradation (Franz, 2014). Indeed, the CI algorithm led to (1) more spatially coherent and temporally consistent Chl patterns, (2) better Chl retrievals than OCx as gauged by field validations, and (3) more consistent cross-sensor time series for low-Chl waters. Consequently, NASA has applied the OCI algorithm as the default Chl algorithm for all ocean color sensors currently being used at NASA, including CZCS, SeaWiFS, MODIS, MERIS, VIIRS, OCTS (Ocean Color and Temperature Sensor; 1996-1997), and GOCI (Geostationary Ocean Color Imager; 2011 to present). This led to a more consistent multisensor time series as shown in the overlapping periods for more than one sensor (Franz, 2014; Franz et al., 2016). Furthermore, inspired by the algorithm design, similar band-difference approaches have been developed to estimate surface concentrations of particulate 
inorganic carbon (Mitchell et al., 2017) and particulate organic carbon (Le et al., 2018), both showing improved performance over the original algorithms.

However, from a practical point of view, several weaknesses still exist in the NASA default global Chl data products. Some of these originate from the algorithm itself while others are due to data processing quality control when generating global products. Specifically,

1. The original CI algorithm was tuned using high-performance liquid chromatography (HPLC) Chl data only. As a result, there are much fewer data points in the CI algorithm training than in the original OCX where both HPLC and fluorometric Chl data were used. The difference between CI algorithm tuning using different data sets needs to be evaluated;

2. During evaluation of the OCI algorithm using global data it was found that the threshold of $0.25 \mathrm{mg} \mathrm{m}^{-3}$ originally proposed by Hu et al. (2012) to transition between CI and OCx could lead to some discontinuity in global data histogram distributions for intermediate $\mathrm{Chl}\left(0.25-0.3 \mathrm{mg} \mathrm{m}^{-3}\right)$. Therefore, the OCI implementation lowered this threshold to $0.175 \mathrm{mg} \mathrm{m}^{-3}$. Consequently, the full advantage of the CI design was compromised because for Chl between 0.175 and $0.25 \mathrm{mg} \mathrm{m}^{-3}$ the band-ratio OCx algorithm still played a role but OCx is less tolerant than CI to input errors. Because $15 \%$ of the global oceans have Chl between 0.175 and $0.25 \mathrm{mg} \mathrm{m}^{-3}$ according to satellite data statistics, it is desirable to extend CI to its original upper bound of $0.25 \mathrm{mg} \mathrm{m}^{-3}$ to take its full advantage;

3. A major advantage of remote sensing is large data quantity (i.e., frequent and synoptic measurements). Current quality control criteria within data processing, however, sometimes make valid retrievals difficult even under cloud-free conditions when bright-target adjacent stray light, Sun glint, large solar or viewing angle, or other nonoptimal observing conditions exist (Feng \& Hu, 2016a). Because the CI algorithm has been shown to be tolerant to many residual correction errors in the algorithm inputs, it might be possible to relax some of the quality control flags to "recover" some of the previously masked data, leading to more valid retrievals without diminishing data quality. Indeed, the problem of no valid retrievals under cloud-free conditions not only reduces coverage, increases uncertainties (due to fewer data points used in calculating the mean), but also presents an obstacle for real-time guidance of ship surveys or monitoring of blooms. Therefore, this problem is briefly reviewed below.

Cloud statistics from MODIS measurements showed that, on average, global ocean cloud fraction is between $70 \%$ and $75 \%$ (King et al., 2013). MODISA has near-daily coverage over subtropical and tropical oceans and daily or more frequent coverage over high-latitude regions. Assuming daily coverage, on average at a given location there should be one cloud-free measurement every three to four days (i.e., about 25-30\% chance). However, after rigorous quality control with the various quality flags applied, global statistics indicated that valid retrievals of $\mathrm{Chl}$ were only $5 \%$ (Feng \& $\mathrm{Hu}, 2016 \mathrm{a}$ ), meaning that for a random 1-km ocean location (before spatial or temporal data binning) there was only one valid retrieval every 20 days. In contrast, valid retrievals for sea surface temperature from the same MODIS measurements nearly doubled to $10 \%$. Clearly, cloud is not the only major factor affecting the quantity of valid retrievals. Others factors such as Sun glint, cloud-adjacent stray light, large solar and/or view angles, and swath width also play important roles. Of these, the straylight flag appeared to be one of the dominant factors.

Stray light near bright targets, such as clouds, is caused by light scattered by the target entering the field of view of the satellite instrument through the sensor's point spread function (Meister \& McClain, 2010). In practice, the MODIS straylight flag was defined as a $7 \times 5$ pixel dilation from any cloud pixel, where 7 is in the cross-track direction and 5 is in the along-track direction (Franz et al., 2005). In other words, a cloud-free pixel within 3 pixels in cross-track direction or 2 pixels in along-track direction from a nearby cloud pixel was considered as being contaminated by clouds and therefore discarded in global data composites. MODIS statistics near clouds indicated that this was perhaps too conservative in masking low-quality cloud-free data, leading to a significant loss of data quantity. Feng and Hu (2016b) showed that although MODIS total radiance even 10 pixels away from clouds may still have significant stray light effect (i.e., $>1 \%$ in total radiance), some of these effects were mitigated through atmospheric correction because the atmospheric correction bands also suffered from the same adjacency effects with the same sign, leading to only 1-2 pixels adjacent to clouds being contaminated by stray light in the retrieved $\mathrm{R}_{\mathrm{rs}}(\lambda)$ values. Based on these results, Feng and $\mathrm{Hu}$ (2016b) argued that the $7 \times 5$ straylight flag might be relaxed to increase data quantity without reducing data quality. However, to what extent the flag can be relaxed is unknown. A thorough evaluation using field data and more statistics is required. 
Therefore, given the potential weakness in the OCI algorithm and a desire to increase data quantity, the objective of this paper is to revisit the OCI algorithm design with its parameterization as well as to improve both data quality and data quantity for global oceans.

\section{Data and Methods}

As in Hu et al. (2012), the focus is on a unified algorithm that can be applied to all ocean color sensors rather than on sensor-specific tuning of parameterization to account for cross-sensor difference in sensor band settings. Such a difference can be corrected through converting the sensor-specific $\mathrm{R}_{\mathrm{rs}}(\lambda)$ to sensor-independent $R_{r s}(\lambda)$ for common, unified wavelengths using hyperspectral $R_{r s}(\lambda)$ data collected from in situ measurements. For this reason, the three wavelengths used in this work are 443, 555, and $670 \mathrm{~nm}$ as a heritage of SeaWiFS.

In situ $\mathrm{R}_{\mathrm{rs}}(\lambda)$ and Chl data from the NASA bio-Optical Marine Algorithm Data set (NOMAD) version 2 were used to refine the Chl algorithm (Werdell \& Bailey, 2005). $\mathrm{R}_{\mathrm{rs}}(\lambda)$ and Chl data were collected by many research groups around the world, thus forming data pairs for algorithm development. To increase data volume, Chl data determined using both HPLC and fluorometric methods were used here. If both measurements were conducted at a station, HPLC Chl was used. Several additional quality-control criteria were applied to the NOMAD data set: $\mathrm{R}_{\mathrm{rs}}(\lambda)>0.0 \mathrm{sr}^{-1}$, Chl $>0.0 \mathrm{mg} \mathrm{m}^{-3}$, and latitude between $60^{\circ} \mathrm{N}$ and $60^{\circ} \mathrm{S}$. A total of 2,306 data pairs were selected.

CI for each data pair was calculated using $\mathrm{R}_{\mathrm{rs}, 443}, \mathrm{R}_{\mathrm{rs}, 555}$, and $\mathrm{R}_{\mathrm{rs}, 670}$ as in Hu et al. (2012):

$$
C I=R_{r s, 555}-\left[R_{r s, 443}+(555-443) /(670-443) x\left(R_{r s, 670}-R_{r s, 443}\right)\right]
$$

In traditional empirical algorithm design, blue/green band ratios have been used to estimate Chl because for most oceanic waters, $\mathrm{R}_{\mathrm{rs}}$ in blue bands decreases with increasing Chl but $\mathrm{R}_{\mathrm{rs}}$ in green bands tends to be relatively stable. Here the maximum ratio, $R$, between four wavelengths of SeaWiFS was estimated as (O'Reilly et al., 2000)

$$
R=\max \left(R_{r s, 443,} R_{r s, 490,} R_{r s, 510}\right) / R_{r s, 555}
$$

In the above equation, the maximum of $R_{r s}$ is selected from three blue bands $(443,490$, and $510 \mathrm{~nm})$ to improve signal-to-noise when the water type changes from clear to more turbid.

Similarly, after the launch of MODIS and VIIRS sensors the maximum ratio $R$ between three wavelengths was also estimated and used in the same fashion in the algorithm development.

Following the NASA approach to derive the OCx algorithm coefficients, Chl data were first gridded into logarithmic space, with the corresponding mean CI and mean $R$ calculated for each grid as described below. Then, for consistency with the NASA approach, such gridded data were gridded again according to $R$ in $\log$ space, with the corresponding mean $\mathrm{Chl}$ and mean $\mathrm{CI}$ calculated and used in the regression to derive the $\mathrm{CI}$ algorithm coefficients using the following algorithm formulation:

$$
\log _{10}(C h l)=a C I+b
$$

where $\mathrm{a}$ and $\mathrm{b}$ are the $\mathrm{CI}$ algorithm coefficients. In practice, the incremental steps in the gridded Chl space were calculated as

$$
L_{, C h l, i}=0.01 x^{1.01}, H_{, C h l, i}=0.01 x(i+1)^{1.01}, i=1-N
$$

where $\mathrm{L}_{, \mathrm{Chl}, \mathrm{i}}$ and $\mathrm{H}_{, \mathrm{Chl}, \mathrm{i}}$ are the lower and upper bounds for the $\mathrm{i}^{\text {th }} \mathrm{Chl}$ bin. The form in equation (4) is to account for lognormal Chl data distributions (Campbell, 1995). For example, the range of the 200th Chl $a$ bin is $0.0732-0.0739$ (i.e., $0.01 \times 200^{1.01}-0.01 \times 201^{1.01}$ ). For all data points whose Chl values fall within a grid, their mean $\mathrm{Chl}$, mean $\mathrm{CI}$, and mean $R$ values were calculated (denoted as $\mathrm{Chl}^{\prime}, \mathrm{CI}^{\prime}$, and $\mathrm{R}^{\prime}$, respectively), resulting in 927 valid bins. These bins were then gridded into the $R$ space again, where the incremental steps in the gridded $\mathrm{R}$ space were calculated as 


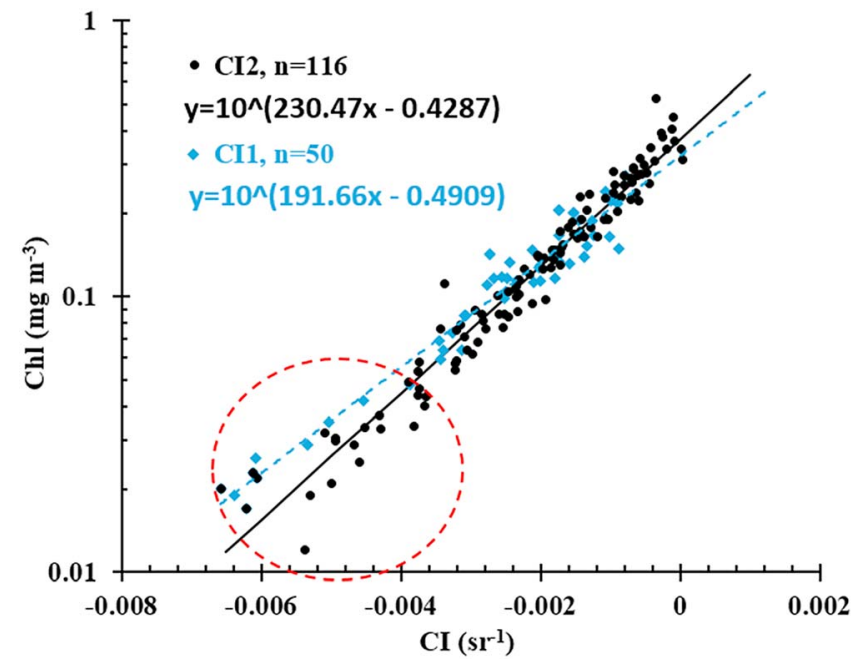

Figure 1. Scatterplot to show the CI2 algorithm. For comparison, the original CI algorithm (CI1) is also presented. The red circle highlights the difference between CI2 and CI1 for low-Chl waters.

$$
L_{, R, i}=0.05 x i^{1.01}, H_{, R, i}=0.05 x(i+1)^{1.01}, i=1-N
$$

where $\mathrm{L}_{, \mathrm{R}, \mathrm{i}}$ and $\mathrm{H}_{, \mathrm{R}, \mathrm{i}}$ are the lower and upper bounds for the $\mathrm{i}^{\text {th }} \mathrm{R}$ bin. The form in equation (5) is to account for the fact that $R$ is not used linearly in the OCx algorithm design, but $\log _{10}(R)$ is used (equation (6)). For all 927 points whose $\mathrm{R}^{\prime}$ values fall within a grid, the mean $\mathrm{Chl}$ and mean CI were calculated (denoted as $\mathrm{Chl}^{\prime \prime}$ and $\mathrm{CI}^{\prime \prime}$, respectively), resulting in 245 final bins.

Of the 245 pairs of $\mathrm{Chl}^{\prime \prime}$ and $\mathrm{CI}^{\prime \prime}$, only 116 pairs with $\mathrm{CI}^{\prime \prime}<0.0001$ (corresponding to $\mathrm{Chl}^{\prime \prime} \sim 0.4 \mathrm{mg} \mathrm{m}^{-3}$ ) were selected to determine the algorithm coefficients using equation (3) (Figure 1).

The CI algorithm is only applicable to low-Chl waters. For higher-Chl waters, the original OCx algorithm is used. For SeaWiFS, the four-band algorithm is specified as (O'Reilly et al., 2000)

$$
\begin{aligned}
& \text { ChloC4 }=10^{y} \\
& y=a_{0}+a_{1} \chi+a_{2} \chi^{2}+a_{3} \chi^{3}+a_{4} \chi^{4}, \chi=\log _{10}(R)
\end{aligned}
$$

where $\mathrm{a}_{0}-\mathrm{a}_{4}$ are the algorithm coefficients determined through nonlinear regression using gridded $\mathrm{Chl}$ and $R$ data as described above. The current algorithm coefficients used operationally by NASA (version 6 ) are $0.3272,-2.9940,2.7218,-1.2259$, and -0.5683 , respectively. The algorithm forms and algorithm coefficients for MODIS and VIIRS are determined similarly. All algorithm forms and coefficients can be found from the NASA algorithm webpage (https:// oceancolor.gsfc.nasa.gov/atbd/chlor_a/).

Because the CI was designed for low-Chl waters only, the global OCI algorithm is a hybrid between CI and OCx, which is formulated as

$$
\begin{aligned}
& \text { Chl }_{O C I}=\text { Chl }_{C I} \quad\left[\text { for Chl }_{C I} \leq C h l_{L} \mathrm{mg} \mathrm{m}^{-3}\right] \\
& \mathrm{Chl}_{\mathrm{OCX}} \quad\left[\mathrm{forChl}_{\mathrm{CI}}>\mathrm{Chl}_{\mathrm{H}} \mathrm{mg} \mathrm{m}^{-3}\right]
\end{aligned}
$$

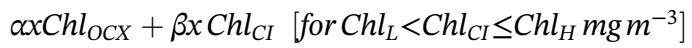

where the weighting factors are $\alpha=\left(\mathrm{Chl}_{\mathrm{CI}}-\mathrm{Chl}_{\mathrm{L}}\right) /\left(\mathrm{Chl}_{\mathrm{H}}-\mathrm{Chl}_{\mathrm{L}}\right), \beta=\left(\mathrm{Chl}_{\mathrm{H}}-\mathrm{Chl}_{\mathrm{CI}}\right) /\left(\mathrm{Chl}_{\mathrm{H}}-\mathrm{Chl}_{\mathrm{L}}\right)$. $\mathrm{Chl}_{\mathrm{L}}$ and $\mathrm{Chl}_{\mathrm{H}}$ define the lower and upper bounds of the algorithm transition zone. In Hu et al. (2012), they were 0.25 and $0.30 \mathrm{mg} \mathrm{m}^{-3}$, respectively. In the NASA operational processing the lower bound was adjusted to $0.175 \mathrm{mg} \mathrm{m}^{-3}$. In this study they are determined to be 0.25 and $0.40 \mathrm{mg} \mathrm{m}^{-3}$ to make the CI design applicable for a higher range while maintaining a smooth transition between the CI and OCx algorithms (see below). On average, SeaWiFS monthly data between 1998 and 2010 showed that $77.8 \pm 1.0 \%$ of the global ocean had $\mathrm{Chl} \leq 0.25 \mathrm{mg} \mathrm{m}^{-3}$ and $5.1 \pm 0.4 \%$ of the global ocean had Chl between 0.25 and $0.3 \mathrm{mg} \mathrm{m}^{-3}$.

Because there are several algorithms used in this paper, for clarity the terminology is defined in Table 1.

Algorithm evaluation was performed using several ways. First, in situ data archived in the NASA SeaWiFS Bio-optical Archive and Storage System (SeaBASS; Werdell et al., 2003) were used to evaluate the Chl data products after applications of the $\mathrm{Chl}$ algorithms. The following search criteria, most of which recommended

Table 1

Algorithm Terminology Used in This Paper

\begin{tabular}{ll}
\hline Algorithm Name & \multicolumn{1}{c}{ Meaning } \\
\hline CI1 & Original CI algorithm with transition zone of $0.25-0.30 \mathrm{mg} \mathrm{m}^{-3}$ (Hu et al., 2012) \\
CI1 & Same as CI1, but the transition zone is adjusted to $0.25-0.40 \mathrm{mg}^{-3}$ \\
CI2 & Adjusted algorithm with new parameterization, with transition zone of 0.25-0.40 $\mathrm{mg} \mathrm{m}^{-3}$ \\
OCI1 & Original OCI algorithm as a hybrid between CI1 and OCx \\
OCI1' & Adjusted algorithm as a hybrid between CI1' and OCx \\
OCI2 & Adjusted algorithm as a hybrid between CI2 and OCx \\
\hline
\end{tabular}


by NASA, were used to find the satellite-in situ matching pairs: bathymetry $>30 \mathrm{~m}$, sensor zenith angle $<56^{\circ}$, solar zenith angle $<70^{\circ}$, $<3$-hr time difference between in situ and satellite measurements, median value of coefficients of variation (calculated as standard deviation divided by mean) of several products $\left(\mathrm{R}_{\mathrm{rs}}\right.$ between 412 and $555 \mathrm{~nm}$, aerosol optical thickness at $865 \mathrm{~nm})<15 \%$ for the $5 \times 5$-pixel window centered at the in situ station, and difference between simulated and measured surface irradiance $<100 \%$; $>50 \%$ pixels in the $5 \times 5$ box must be valid (i.e., not associated with any of the standard quality-control flags such as straylight and high glint; Bailey \& Werdell, 2006). A total of 1,424 matching pairs were selected for SeaWiFS between 1998 and 2010, and 330 were obtained for MODIS Aqua between 2002 and 2010. These are basically the same data sets as used in Hu et al. (2012).

Second, in addition to the approach above for product evaluation, additional effort was used to find in situ data collected under MODIS straylight mask. To achieve this, all concurrent and collocated MODIS and in situ matching pairs were downloaded from NASA without applying any criteria above except that the time window was relaxed from \pm 3 to $\pm 4 \mathrm{hr}$. The same was performed to find the corresponding SeaWiFS files. A total of 3,728 MODIS level-2 files and 5,763 SeaWiFS MLAC level-2 files were downloaded for this purpose. Then, local processing (instead of using the SeaBASS search engine) was used to apply all but the straylight flag to determine which in situ data points were associated MODIS straylight flag. Unfortunately, there were only $<5$ points qualified for such criteria, making it impossible to evaluate MODIS retrievals under the $7 \times 5$ straylight flag using in situ measurements. Thus, statistical analysis using satellite data alone is the only approach to determine whether these $7 \times 5$ flagged pixels are statistically different from the adjacent, non-flagged pixels.

\section{Results}

\subsection{Refined OCI Algorithm (OCI2) and Its Field Validation}

Figure 1 shows the new CI algorithm (CI2) based on all qualified NOMAD Chl data and $\mathrm{R}_{\mathrm{rs}}(\lambda)$ data after gridding in log space. For comparison, the original CI algorithm (hereafter CI1; Hu et al., 2012) is also shown. Although they are similar between Chl of $0.1-0.2 \mathrm{mg} \mathrm{m}^{-3}$, there are noticeable differences for $\mathrm{Chl}<0.05 \mathrm{mg} \mathrm{m}^{-3}$ (red circle) and for $\mathrm{Chl}>0.3 \mathrm{mg} \mathrm{m}^{-3}$. The differences are due to their different inputs of Chl and $\mathrm{R}_{\mathrm{rs}}(\lambda)$ data because CI1 used the limited HPLC data only while CI2 used all data including HPLC and fluorometric Chl. From a pure statistical point of view, with the limited data, however, it is difficult to conclude which one is superior. This is especially true for $\mathrm{Chl}<0.05 \mathrm{mg} \mathrm{m}^{-3}$ where data spread around the fitting line is significantly higher than for other Chl values. Also note that for the same CI values (i.e., same input $\mathrm{R}_{\mathrm{rs}}(\lambda)$ data), $\mathrm{Chl}_{\mathrm{CI} 2}$ is lower than $\mathrm{Chl}_{\mathrm{CI} 1}$ for $\mathrm{Chl}<0.05 \mathrm{mg} \mathrm{m}^{-3}$. This will have significant impact on studies of ocean gyres where Chl is extremely low.

The OCI2 algorithm was applied to both SeaWiFS and MODISA data where concurrent field-measured Chl data were available through NASA's SeaBASS archive. Such estimated Chl $\mathrm{OCI}_{2}$ were compared with fieldmeasured $\mathrm{Chl}$ in Figure 2 using the search criteria described above. For comparison, Chl data derived from SeaWiFS and MODISA using the OCx algorithm are also presented in Figure 2, while statistical measures of the algorithm performances for low-Chl waters are all listed in Table 2.

The evaluation results show that compared with the OCx algorithm, OCI2 performance is significantly better in nearly all statistical measures for low-Chl waters. Hu et al. (2012) showed that even if the OCx algorithm coefficients were retuned using low $\mathrm{Chl}$ data $\left(<0.4 \mathrm{mg} \mathrm{m}^{-3}\right)$ only, the CI algorithm design still led to improved algorithm performance than OCx because of the former's tolerance to input $\mathrm{R}_{\mathrm{rs}}(\lambda)$ errors (admittedly that all in situ $R_{r s}(\lambda)$ data still contain a few percent errors or uncertainties even after rigorous quality control). Compared to OCI1, OCI2 performance measures are mixed when these discrete in situ measurements were used to evaluate product uncertainties, but they are generally comparable to those of OCI1. One obvious and also previously known finding is the significant data spread for almost the entire data range, highlighting the need for improved data quality in field measurements. Most importantly, data are extremely scarce from ocean gyres where Chl is low. For MODISA, there is not a single point with in situ $\mathrm{Chl}<0.03 \mathrm{mg} \mathrm{m}^{-3}$. For SeaWiFS, there is not a single point with in situ Chl $<0.02 \mathrm{mg} \mathrm{m}^{-3}$, and data for

$\mathrm{Chl}<0.1 \mathrm{mg} \mathrm{m}^{-3}$ appear to be more spread than in other ranges. Clearly, the puzzle of which one is closer 

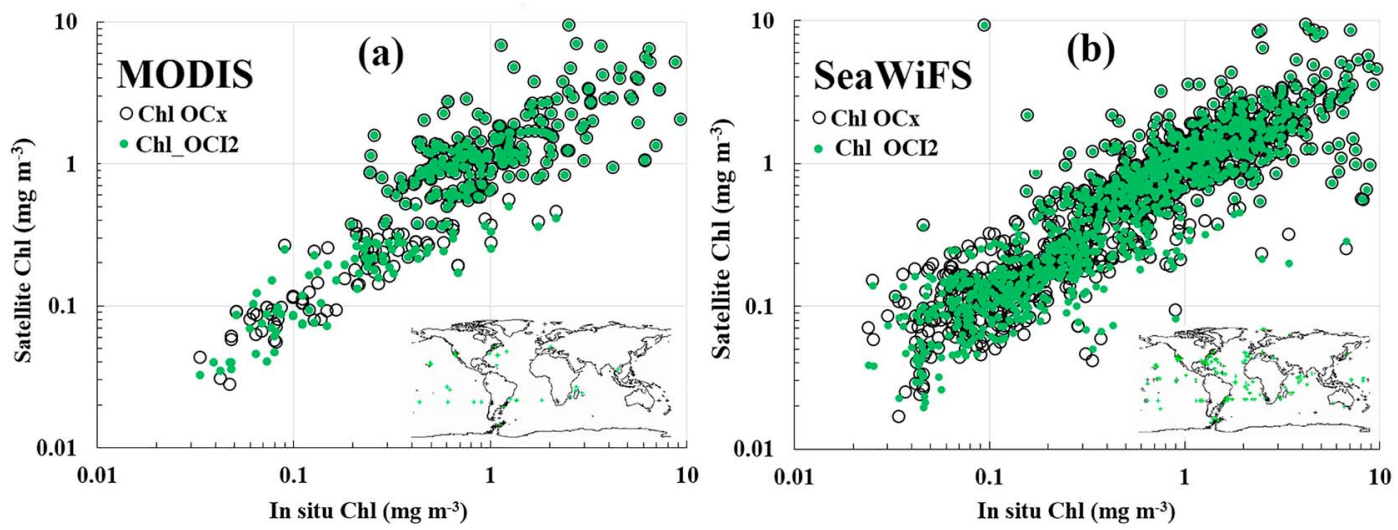

Figure 2. Evaluation of the OCI2 algorithm with SeaBASS data. For comparison, performances of the OCx algorithms are also presented. The inset figures show the locations of the satellite-in situ matching pairs. The statistical measures for lowChl waters can be found in Table 2 .

to the "truth" for low-Chl waters, $\mathrm{Chl}_{\mathrm{CI} 1}$ or $\mathrm{Chl}_{\mathrm{C} 22}$ in Figure 1, cannot be resolved from evaluations using the current in situ data sets. Other measures, as shown below, may be used to determine which one is better.

\subsection{OCI2 Performance by Other Measures}

Although scatterplots have been widely used for algorithm evaluation, they only provide one side of the story because (1) field data are always limited, and they may not cover the full range under all possible measurement scenarios, and (2) more importantly, potential artifacts in image quality and cross-sensor inconsistency cannot be revealed by scatterplots. Therefore, data statistics, image quality, and cross-sensor consistency are examined in order to further evaluate the OCI2 performance.

The first check is on Chl continuity in the transition zone, which is $0.25-0.3 \mathrm{mg} \mathrm{m}^{-3}$ for OCI1 but $0.25-0.4$ for OCI2. For an apple-to-apple comparison, an adjusted OCI1 (i.e., OCI1' in Table 1) with the same transition zone of $0.25-0.4 \mathrm{mg} \mathrm{m}^{-3}$ was tested as well. This is because if a smoother transition zone is achieved it is easier to verify whether it is due to algorithm change from CI1 to CI2 or due to transition zone change from $0.25-0.3$ to $0.25-0.4 \mathrm{mg} \mathrm{m}^{-3}$. Here the transition thresholds of 0.25 and $0.4 \mathrm{mg} \mathrm{m}^{-3}$ correspond to the clearwater definition given by Gordon and Clark (1981) and the upper limit of the CI algorithm applicability (Figure 1), respectively. The comparison between these three schemes is shown in Figure 3. The discontinuity in OCI1 largely disappeared in OCI1' and OCI2, with the latter two showing slightly different histogram distributions due to their different algorithm coefficients (Figure 1). Overall, OCI2 appears to have significantly reduced the discontinuity in Chl distribution across the transition zone for all three sensors examined.

Next, the three OCI algorithms are compared against the default OCx algorithm for the same images as used in Figure 3, with results shown in Figure 4. Compared to OCI1, both OCI1' (black dots) and OCI2 (red dots)

Table 2

Performance of the Updated Chl Algorithm (CI2) for Both MODISA and SeaWiFS for Chl $<0.25 \mathrm{mg} \mathrm{m}^{-3}$, as Gauged by Field-Measured Chl From NASA's SeaBASS Data Archive

\begin{tabular}{lccccccccc}
\hline & & RMSE & URMSE & Mean Ratio & Median Ratio & MRE & $R^{2}$ & $R^{2}(\log )$ & $N$ \\
\hline MODISA & OCx & $77.7 \%$ & $44.2 \%$ & 1.24 & 1.05 & $32.0 \%$ & 0.42 & 0.66 & 63 \\
& CI1 & $43.9 \%$ & $32.7 \%$ & 1.15 & 1.04 & $25.4 \%$ & 0.62 & 0.71 & 63 \\
& CI2 & $51.2 \%$ & $37.6 \%$ & 1.12 & 0.94 & $35.2 \%$ & 0.59 & 0.71 & 63 \\
SeaWiFS & OCx & $535.8 \%$ & $54.2 \%$ & 1.79 & 1.19 & $41.5 \%$ & 0.01 & 0.33 & 357 \\
& CI1 & $91.8 \%$ & $47.2 \%$ & 1.40 & 1.16 & $36.8 \%$ & 0.31 & 0.39 & 357 \\
& CI2 & $102.0 \%$ & $49.6 \%$ & 1.38 & 1.14 & $39.4 \%$ & 0.28 & 0.39 & 357 \\
\hline
\end{tabular}

Note. For comparison, performances of the original CI1 (Hu et al., 2012) and the OCx algorithms are also listed. Definitions and meanings of the statistical terms can be found in Hu et al. (2012). RMSE: root-mean-square error, URMSE: unbiased RMSE, MRE: mean relative error. 


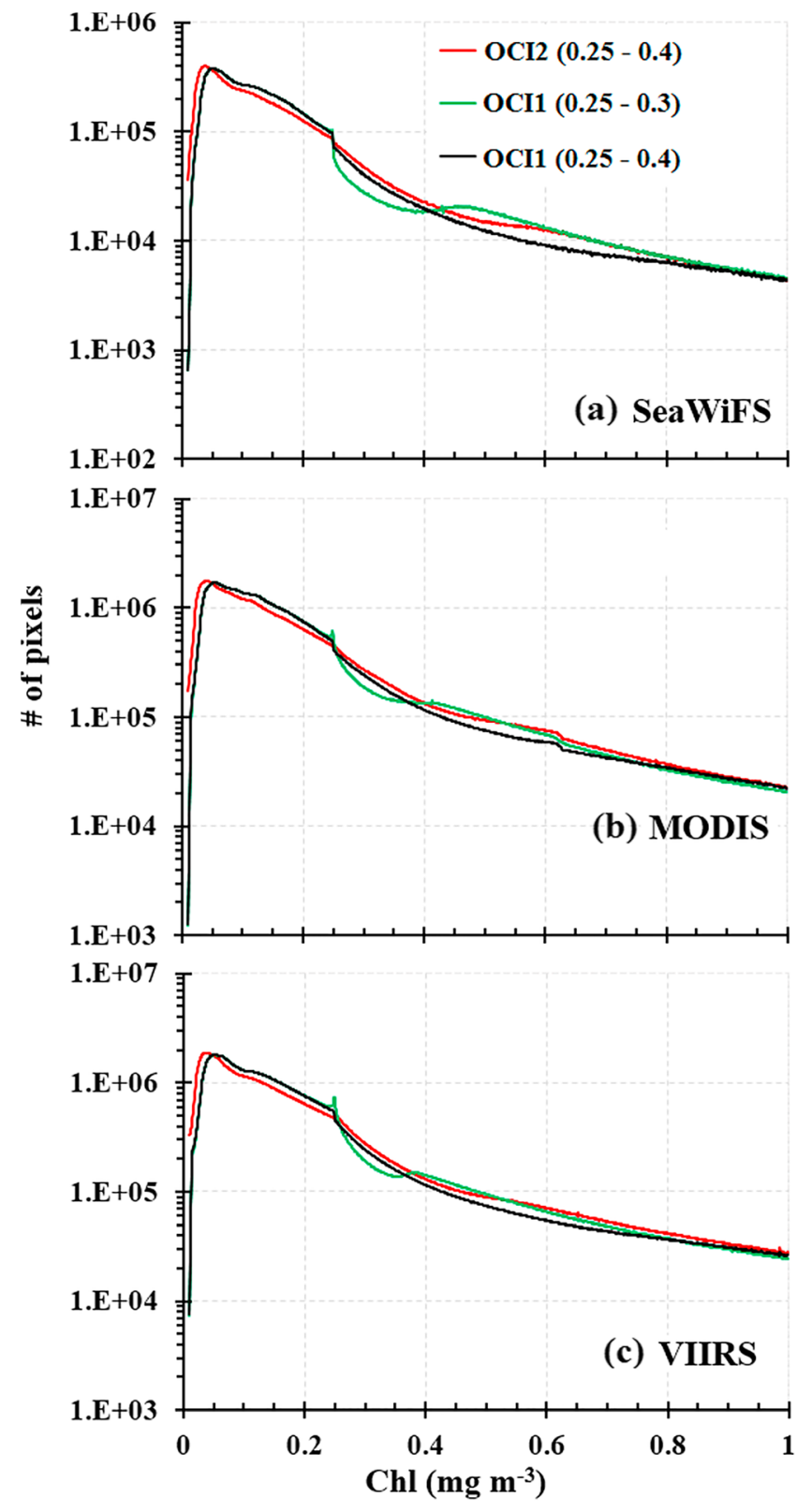

Figure 3. Improvements of OCI2 over OCI1 in the algorithm transition zone of $0.25-0.4 \mathrm{mg} \mathrm{m}^{-3}$ for all three sensors. Global level-3 daily $\mathrm{R}_{\mathrm{rs}}$ composites in 2010 (365 daily composites) were used to generate the histogram distributions for MODISA and SeaWiFS, and 365 global daily level-3 $\mathrm{R}_{\mathrm{rS}}$ composites in 2014 were used for VIIRS. The wavelengths of MODIS and VIIRS green bands (547 and $551 \mathrm{~nm}$, respectively) were adjusted to $555 \mathrm{~nm}$ using empirical relationships between these bands derived from NOMAD data. showed smoother transition (i.e., no apparent "bump") between low and higher Chl ranges. However, compared to OCI1', OCI2 is closer to $\mathrm{OCx}$ around the 1:1 line for $\mathrm{Chl}>0.2 \mathrm{mg} \mathrm{m}^{-3}$ and especially for $\mathrm{Chl}>0.4 \mathrm{mg} \mathrm{m}^{-3}$, suggesting that OCI2 is likely better in algorithm consistency when considering that $\mathrm{OCx}$ is actually the algorithm used for $\mathrm{Chl}>0.4 \mathrm{mg} \mathrm{m}^{-3}$. Subtle but noticeable difference was found for $\mathrm{Chl}>0.2 \mathrm{mg} \mathrm{m}^{-3}$, which does not indicate poor OCI algorithm performance because by algorithm design $\mathrm{CI}$ is different from OCx and this difference can also show up in the transition zone. Because in the transition zone the weighted mixing (equation (7)) is based on $\mathrm{Chl}_{\mathrm{CI}}$, OCI2 and $\mathrm{OCx}$ do not merge exactly on the $1: 1$ line even after $\mathrm{Chl}>0.4 \mathrm{mg} \mathrm{m}^{-3}$. Statistically it is difficult to determine which algorithm is closer to the truth due to significant data spread in this range and due to the small difference between CI1 and CI2 (Figure 1). However, an algorithm should have smooth transition between low-Chl and higher-Chl waters. In this regard, OCI2 appears to have better performance than either OCI1 $(0.25-0.3)$ or OCI1 (0.25-0.4; i.e., OCI1').

The effect of OCI2 on image quality is significant when the OCx image is used as a reference to compare with (Figure 5). This is similar to the OCI1 effect shown in Hu et al. (2012). Most of the noise due to cloud-adjacent stray light contamination, shown clearly in the OCx image, disappeared in both OCI1 and OCI2 images. This effect is what the algorithm concept was designed for (Hu et al., 2012). For this gyre location OCI2 showed lower Chl than OCI1, which was also closer to $\mathrm{OCx}$ (not necessarily more accurate, however), a result of adjustment of the algorithm coefficients (Figure 1).

The OCI2 and OCx algorithms are further compared in their global monthly MODIS Chl maps in Figure 6. Visually, they appear similar in all major spatial patterns as well as Chl magnitudes except that OCI2 $\mathrm{Chl}$ maps are more spatially coherent because most of the noise-induced errors for low-Chl waters have been removed in the band difference design (Hu et al., 2012; such a contrast can only be visualized in the full-size versions of the images). However, their relative difference images clearly show disparity across major ocean basins. For example, during winter months (January and March), $\mathrm{Chl}_{\mathrm{OCx}}$ is mostly lower than $\mathrm{Chl}_{\mathrm{OCI} 2}$ for North Atlantic and North Pacific, but during the month of June the opposite is observed. Similar to those from the scatterplot evaluations, however, it is difficult to conclude from these results alone which algorithm is closer to the truth.

The most significant improvement of the CI design is on cross-sensor consistency, as shown in Hu et al. (2012). Such an improvement is illustrated again in Figure 7, where histograms of monthly Chl distributions for oligotrophic oceans (defined by SeaWiFS mission climatology $\mathrm{Chl}<0.1 \mathrm{mg} \mathrm{m}^{-3}$ ), derived from OCx, OCI1, and OCI2 algorithms, are compared between SeaWiFS and MODISA and between VIIRS and MODISA. The distributions from OCx showed large cross-sensor differences that are difficult to observe from image inspection or scatterplot evaluations. Such differences are largely removed in both OCI1 and OCI2, where they show nearly identical cross-sensor distributions.

The improvement in cross-sensor consistency is further shown in Figure 8, where global mean Chl of oligotrophic oceans (defined by SeaWiFS mission climatology $\mathrm{Chl}<0.1 \mathrm{mg} \mathrm{m}^{-3}$ ) are compared between SeaWiFS and MODISA and between VIIRS and MODISA using their ratios. A perfect cross-sensor consistency would result in a ratio of 1.0 for all months. The $\mathrm{OCx}$ algorithms are associated with relatively large 


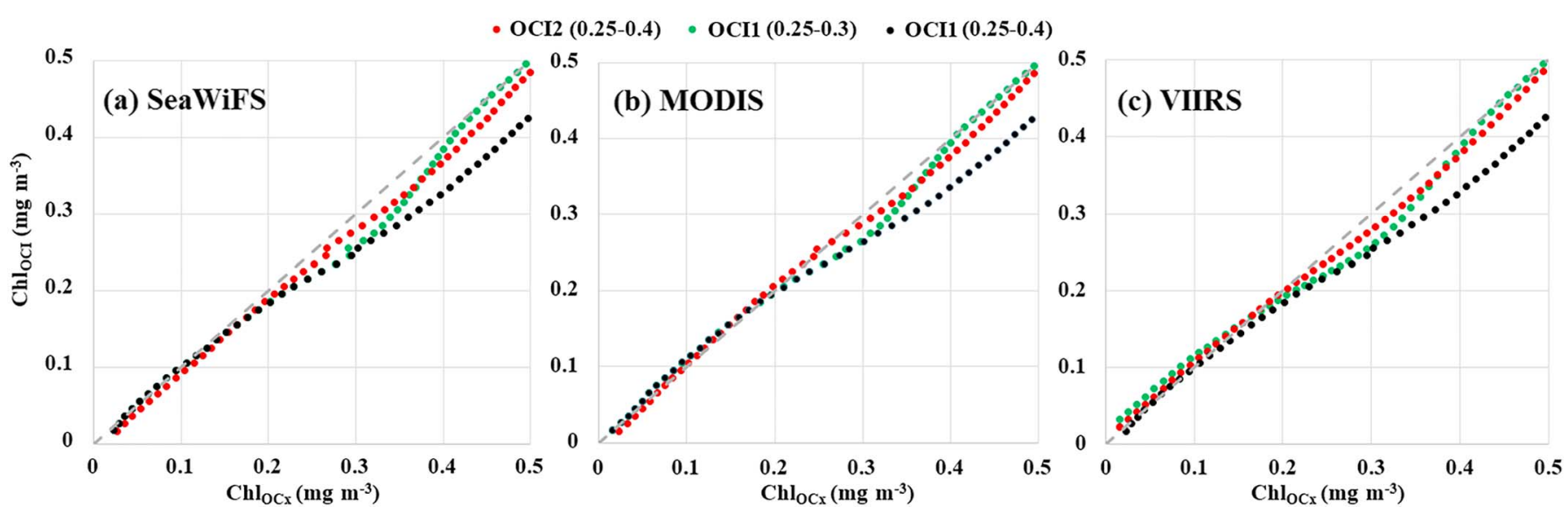

Figure 4. Comparison between OCx ( $x$ axis) and OCI1 and OCI2 ( $y$ axis) for three ocean color sensors. The gray dashed line of each panel indicates the 1:1 line. The results were generated using the entire global level-3 daily $\mathrm{R}_{\mathrm{rs}}$ data sets in 2010 for MODIS and SeaWiFS and in 2014 for VIIRS, respectively. Here OCII $(0.25-0.4)$ is termed as OCI1 ${ }^{\prime}$ in Table 1 . Note that OCI and OCx do not merge exactly on the 1:1 line even after the upper bound of the transition zone because the weighted mixing in equation (7) is based on $\mathrm{Chl}$ CI.

cross-sensor discrepancies (about 10\%), while both OCI1 and OCI2 reduced such discrepancies significantly to $1-2 \%$.

In summary, similar to the original OCI1, the OCI2 algorithm showed improvements over the OCx algorithms in production of equivalent or better Chl values for low-Chl waters, but more importantly, far improved image quality and cross-sensor consistency. Furthermore, it reduced the discontinuity in the algorithm transition zone. Therefore, future data processing may adopt OCI2 as an update of OCI1.

\subsection{Data Recovery}

The MODIS default $7 \times 5$ straylight mask was changed to $0 \times 0$ (i.e., no straylight), $3 \times 3,5 \times 3$, and $9 \times 7$. Because in situ data could not be found from the entire SeaBASS archive corresponding to these masked pixels, statistics of image data alone was used to evaluate their potential differences.

Figure 9 shows the Chl histogram distributions from pixels with different masking schemes. The evaluation was performed from pixels of 665 MODISA images for all "rings" near cloud edges. The first ring includes the cloud-free pixels with " 0 " distance to cloud edge, that is, those between the $0 \times 0$ and $3 \times 3$ masks. The second ring includes cloud-free pixels between the $3 \times 3$ and $5 \times 3$ masks, and so on. Figure 9a shows that except for the first ring (black line), all other rings have similar histogram distributions, especially when considering that they are comparable to those pixels traditionally considered as being not influenced by stray light (i.e., between $7 \times 5$ and $9 \times 7$ ). This is not a surprise, as the tolerance of the OCI design to input errors has already been demonstrated in $\mathrm{Hu}$ et al. (2012). What is surprising is that for the 665 evaluated MODISA images, OCx also appears to be tolerant to stray light after a $3 \times 3$ masking (Figure $9 \mathrm{~b}$ ). Indeed, other than the first ring (i.e., $3 \times 3$ masked pixels), all other rings show similar histogram distributions. These results indicate that the $7 \times 5$ straylight mask might be relaxed to $3 \times 3$ in order to increase data quantity without losing data quality.

The statistics on Chl distributions were from 665 MODISA images over clear waters in the North Atlantic gyre. To evaluate whether the same observations can also be made to $R_{r s}(\lambda)$, the same statistical analysis was performed for the 665 MODISA images, but with the focus on $\mathrm{R}_{\mathrm{rs}}(\lambda)$ instead of Chl. Our rationale is that conclusions drawn from the $\mathrm{R}_{\mathrm{rs}}(\lambda)$ statistics over clear waters may be extended globally (including coastal waters).

Figure 10 shows that similar to the Chl distributions, except for the pixels immediately adjacent to cloud edges (i.e., $3 \times 3$ masking), all other rings have similar histogram distributions, meaning that statistically pixels in the ring between $3 \times 3$ and $7 \times 5$ are not different from those between $7 \times 5$ and $9 \times 5$ masking. The importance of this finding is that because $\mathrm{R}_{\mathrm{rs}}(\lambda)$ serves as the inputs for nearly all bio-optical inversion algorithm (including $\mathrm{Chl}$ algorithms), the straylight flag may be relaxed from the current $7 \times 5$ to the new $3 \times 3$ pixels for possibly all ocean color data products including Chl, of course pending further evaluations on specific data products. Indeed, results from the same analysis over all MODISA images over the Gulf of Mexico 

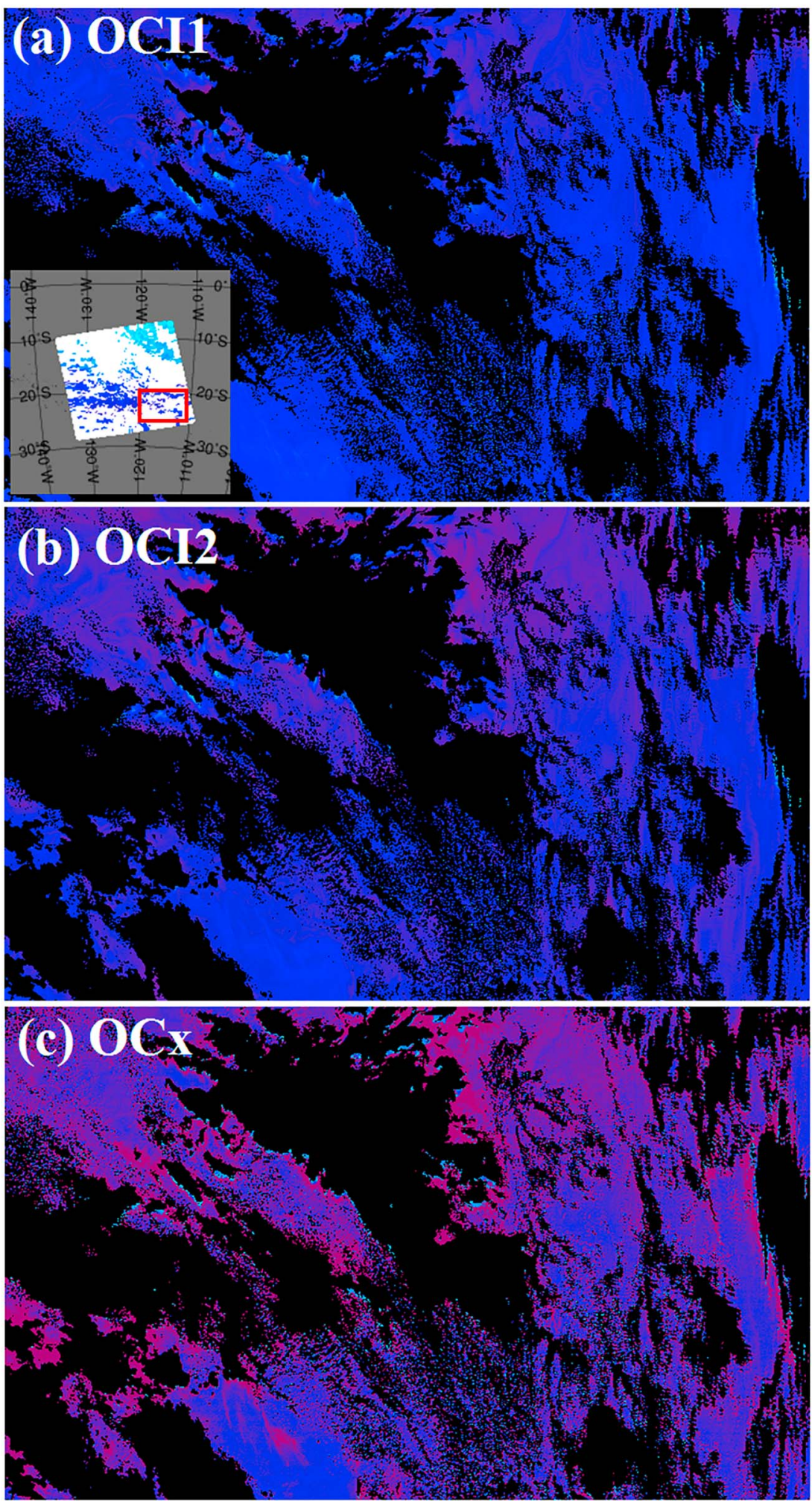

Chlorophyll a concentration $\left(\mathrm{mg} / \mathrm{m}^{3}\right)$

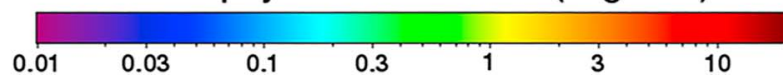

Figure 5. Comparison between Chl images (approximately 1,000 km wide) derived from three algorithms for MODIS data collected on 30 August 2004 over the South Pacific gyre (subscene from the inset figure). 


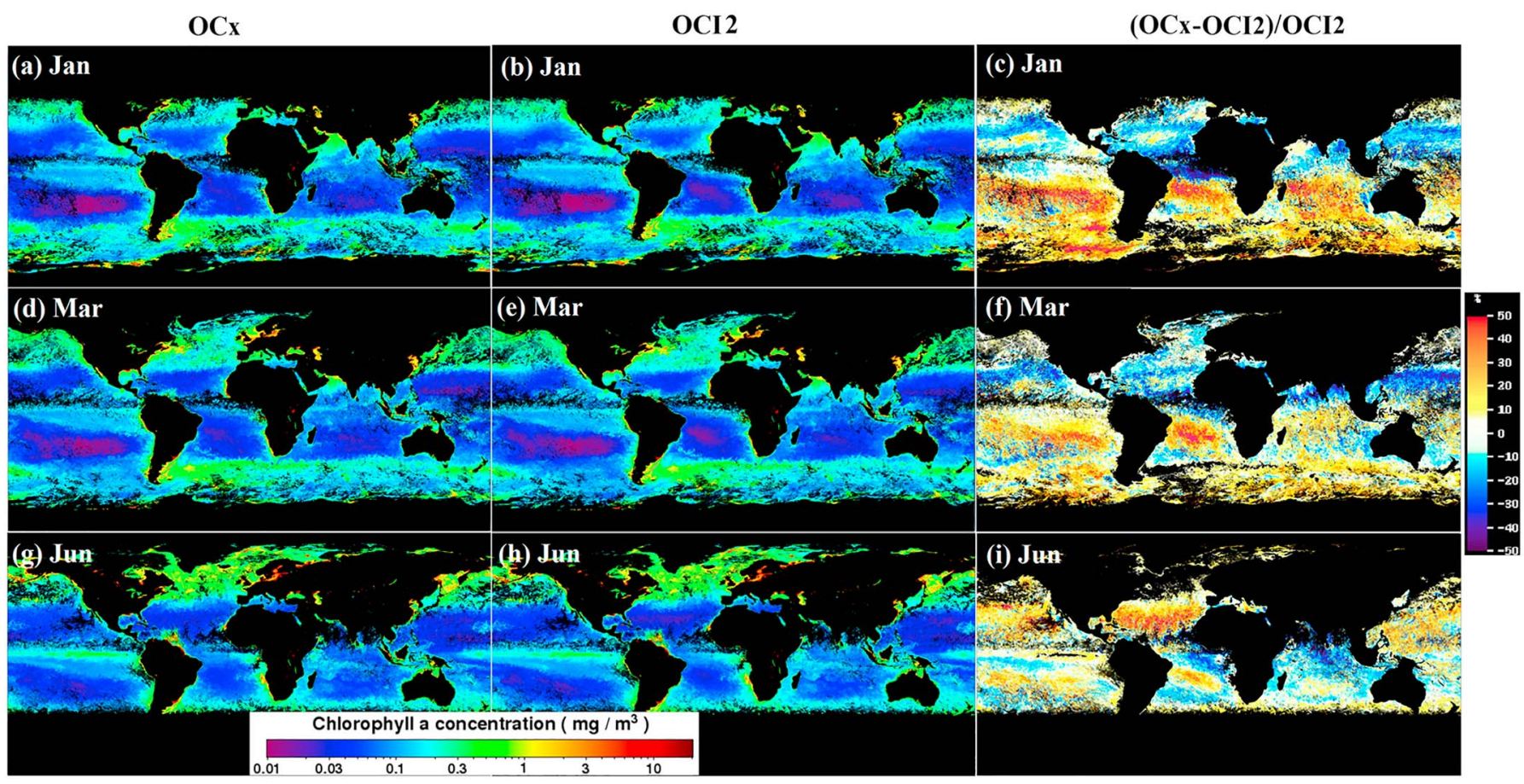

Figure 6. Comparison of global monthly $\mathrm{Chl}$ maps derived from (left column) OCx and (middle column) OCI2 for different months of 2010, which were derived using daily level- $3 \mathrm{R}_{\mathrm{rs}}$ composites. The right column shows their relative differences.

during 2010 indicate that even when pixels are restricted to waters with $\mathrm{Chl}>0.4 \mathrm{mg} \mathrm{m}^{-3}$, pixels in every ring (except the $3 \times 3$ ring) around cloud edge have near-identical histogram distributions in either spectral

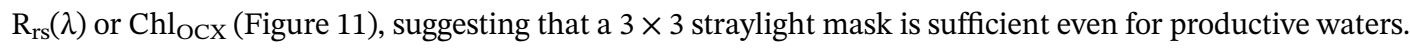

Based on these results, the relaxed $3 \times 3$ straylight flag was applied to global level-2 OCI2 data for March and July 2005 to generate new global mean $\mathrm{Chl}_{\mathrm{OCI2}}$ maps with a 9-km resolution grid, which were compared with the current (default) $\mathrm{Chl}_{\mathrm{OCI} 2}$ maps. The results are shown in Figure 12. Some of the data gaps in the default $\mathrm{Chl}_{\mathrm{OCI} 2}$ maps are filled in the new maps after relaxing the straylight mask from $7 \times 5$ to $3 \times 3$ pixels. These are particularly apparent in the equatorial Pacific and Atlantic within the Intertropical Convergence Zone, the North Atlantic, the North Indian Ocean, and the Southern Ocean (all circled in red in Figure 12). Figures $12 \mathrm{e}$ and $12 \mathrm{f}$ show the comparison between the monthly mean $\mathrm{Chl}_{\mathrm{OCI}}$ derived from the default $7 \times 5$ masking and the new $3 \times 3$ masking. To reduce pepper noise from individual 9-km pixels, spatial binning was performed first. Although the changes in $\mathrm{Chl}_{\mathrm{OCI} 2}$ between the two masking schemes are relatively small (within a few percent), there are some spatially coherent patterns, for example, slightly lower $\mathrm{Ch}_{\mathrm{OCI} 2}$ in the Southern Ocean and waters off Peru (in July 2005) from the new masking scheme.

The increased coverage and different monthly mean Chl from the relaxed straylight masking are all due to the increased number of valid observations in every $9-\mathrm{km}$ grid cell. Figure 13 shows the comparison between number of valid level-2 pixels used to calculate the monthly mean from the $7 \times 5$ and $3 \times 3$ masking schemes. Globally, the relative increases in the number of valid level-2 pixels are $~ 39 \%$ for both months, but the increases can be more significant in many regions, often reaching $>100 \%$ as indicated by the green and colder colors in Figures 13e and 13f. In the North Indian Ocean, the increases reached $400 \%$ in July 2005 (i.e., the ratio is $\sim<0.2$ in the maps).

\section{Discussion}

\subsection{Need for More Field Data From Ocean Gyres}

Each time satellite data are reprocessed with new calibration or new algorithm the resulting data products are changed, and most times with improvements. To date, data from all sensors have been reprocessed several times by NASA, with the OCI1 algorithm incorporated during the most recent reprocessing (2014.0 and 

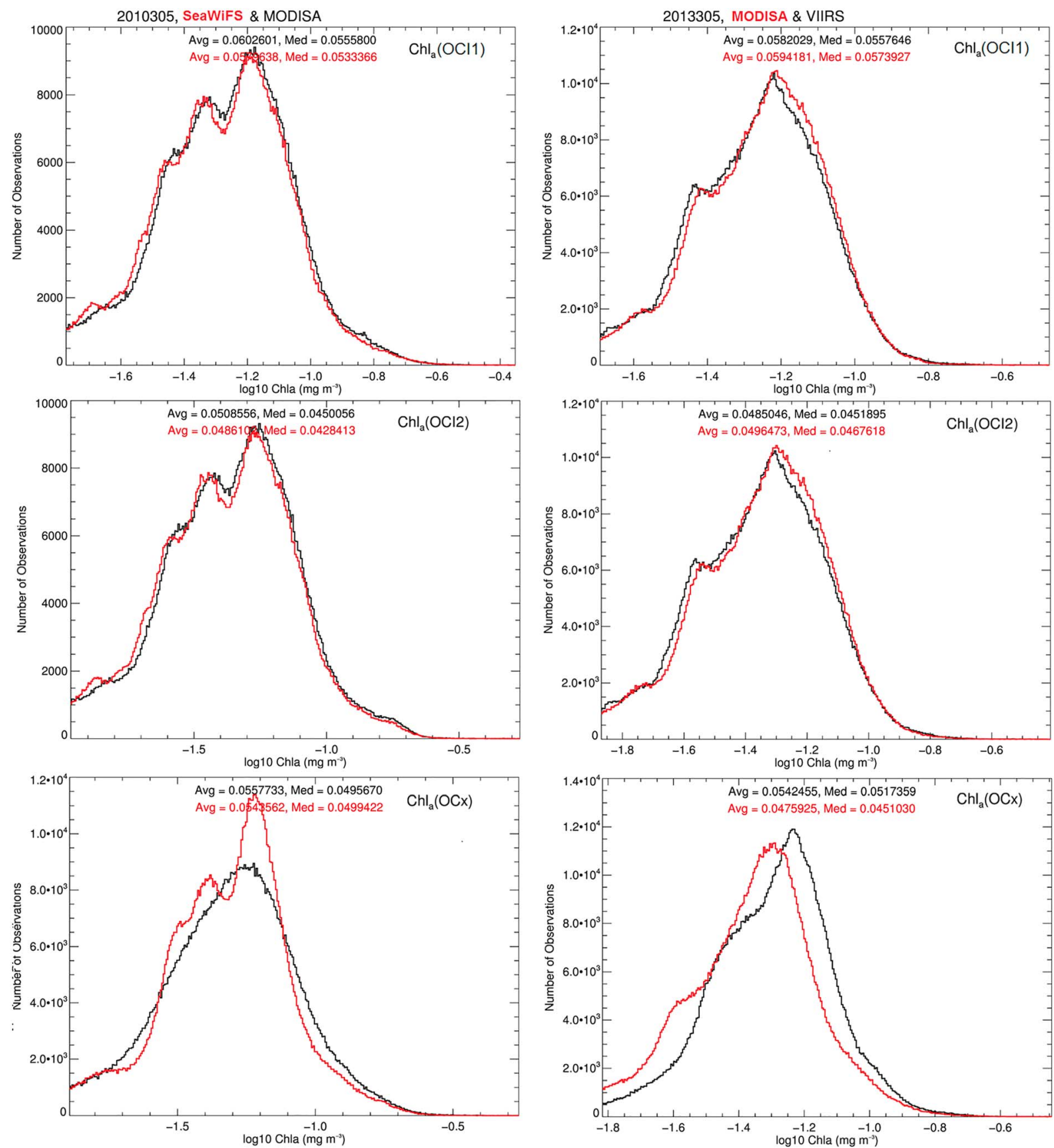

Figure 7. Comparison of Chl distributions from global oligotrophic oceans (geographic extent defined by SeaWiFS Chl climatology $\leq 0.1 \mathrm{mg} \mathrm{m}^{-3}$, where actual Chl during a specific month can be $0.4 \mathrm{mg} \mathrm{m}^{-3}$ (corresponding to $\log 10(\mathrm{Chl})=-0.4$ ) or higher) obtained from three algorithms. The comparison was made (left column) between SeaWiFS and MODISA and (right column) between VIIRS and MODISA.

2018.0) for its advantages over the traditional OCx algorithms. The results shown here demonstrate that OCI 2 may be a better choice. This is because that while its absolute accuracy is similar to OCI1 as gauged by the in situ validation statistical measures and its cross-sensor consistency is also comparable to OCI1, its applicability range is extended to $0.4 \mathrm{mg} \mathrm{m}^{-3}$ with smoother algorithm transition between 0.25 and $0.4 \mathrm{mg} \mathrm{m}^{-3}$ than OCI1.

One large difference between OCI2 and OIC1 is their Chl retrievals for low concentration waters $\left(<0.05 \mathrm{mg} \mathrm{m}^{-3}\right)$, mostly over ocean gyres. These account for about $14.7 \pm 2 \%$ of the global ocean area according to SeaWiFS monthly statistics between 1998 and 2010. From a statistical point of view, however, it is 


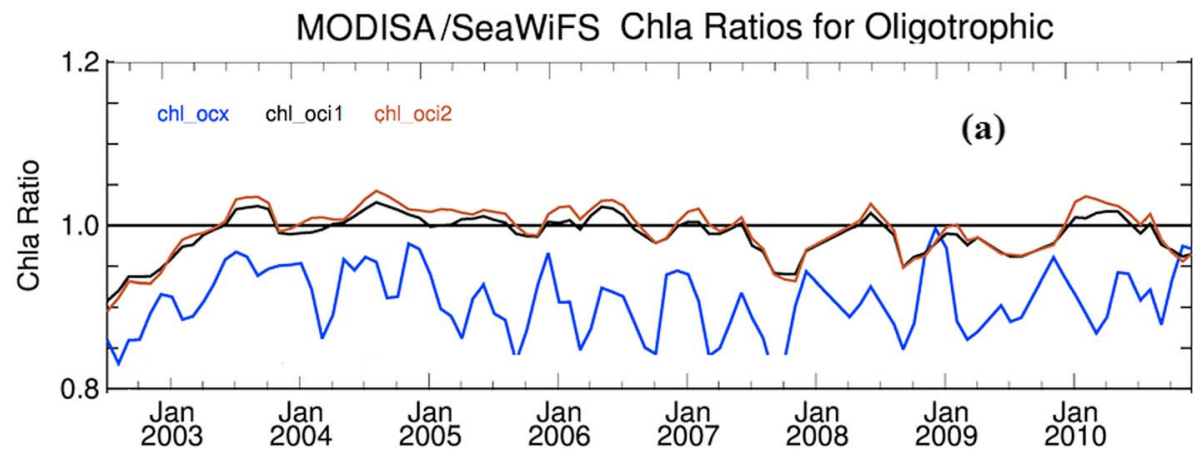

VIIRS/MODISA Chla Ratios for Oligotrophic

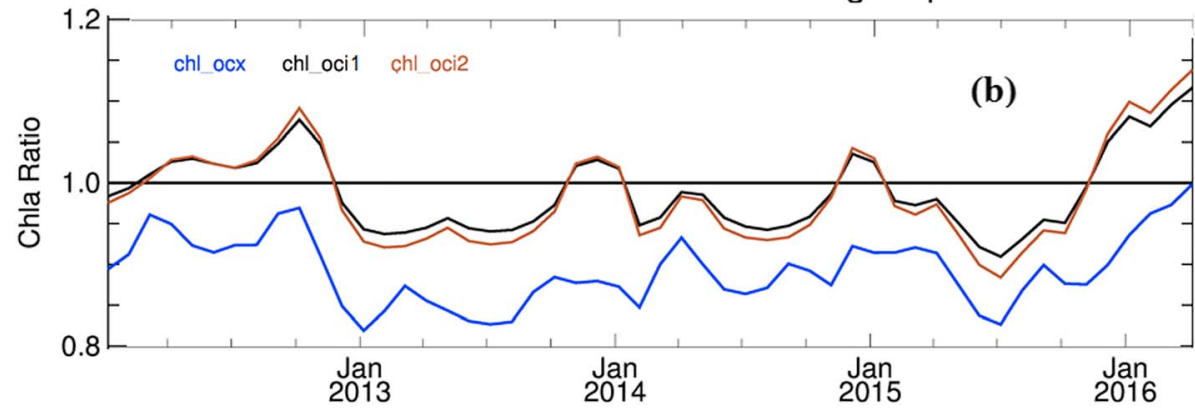

Figure 8. Mean Chl ratios over global oligotrophic oceans (geographic extent defined by SeaWiFS Chl climatology $\leq 0.1 \mathrm{mg} \mathrm{m}^{-3}$, where actual Chl during a specific month can be $0.4 \mathrm{mg} \mathrm{m}^{-3}$ (corresponding to $\log 10(\mathrm{Chl})=-0.4$ ) or higher) between different sensors using three different algorithms. (a) MODISA/SeaWiFS. (b) VIIRS/MODISA. In (a), the long-term mean monthly ratios are $0.91 \pm 0.04,0.99 \pm 0.03$, and $1.00 \pm 0.03(N=102)$ for OCx, OCI1, and OCI2, respectively. In (b), the long-term mean ratios are $0.89 \pm 0.04,0.98 \pm 0.04$, and $0.98 \pm 0.05(N=50)$ for OCx, OCI1, and OCI2, respectively.

difficult to know which algorithm yielded better (i.e., more accurate) results due to the extreme data scarcity from field measurements and the general uncertainties associated with collecting in situ Chl in these very clear waters. The significant data spread for $\mathrm{Chl}<0.05 \mathrm{mg} \mathrm{m}^{-3}$ in Figure 1 also suggest possible errors in the field-measured Chl or $\mathrm{R}_{\mathrm{rs}}(\lambda)$ because bio-optical properties over ocean gyres are expected to be very stable between Chl and $\mathrm{R}_{\mathrm{rs}}(\lambda)$. The reason for data scarcity is possibly due to the remote locations, while the reason for erroneous data may possibly be due to difficulty in obtaining reliable in situ $\mathrm{R}_{\mathrm{rs}}(\lambda)$ data and due to the requirement of large volume of waters to be filtered to obtain a measurable signal from these extremely low-Chl waters. Indeed, even after applying additional quality control to the NOMAD $\mathrm{R}_{\mathrm{rs}}(\lambda)$ data using a recently developed scoring system (Wei et al., 2016), it is still impossible to determine which

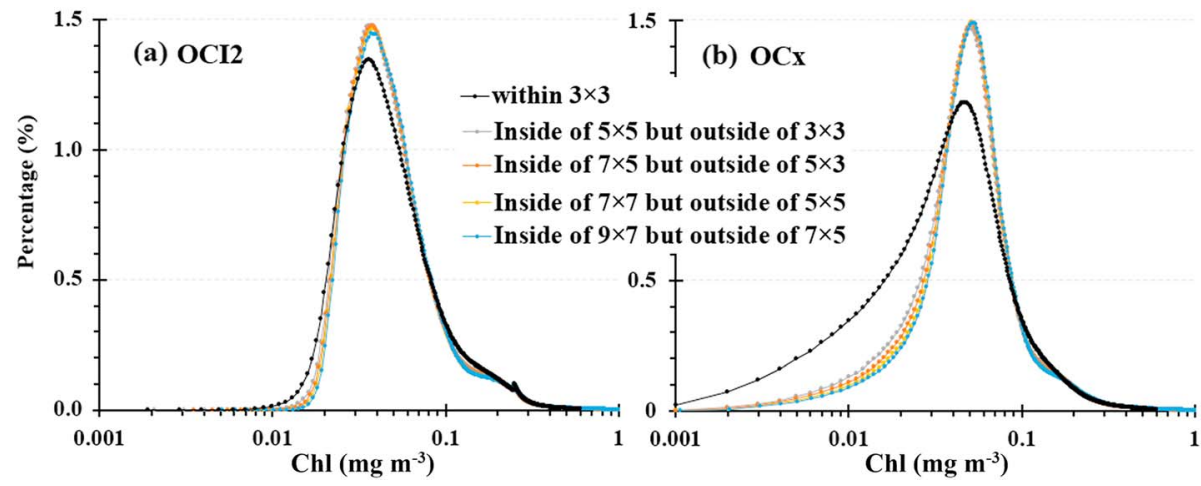

Figure 9. Histograms of (a) $\mathrm{Chl}_{\mathrm{OCI} 2}$ and (b) $\mathrm{Chl}_{\mathrm{OCx}}$ from pixels near cloud edges after applying different masking methods. The statistics were derived from 665 MODISA images in 2010 over the North Atlantic gyre $\left(60^{\circ}-40^{\circ} \mathrm{W}, 15^{\circ}-35^{\circ} \mathrm{N}\right)$. Note that except for pixels in the first "ring" (i.e., within $3 \times 3$ pixels of cloud edge), pixels from all other rings, including those outside the default $7 \times 5$ straylight mask, have similar histogram distributions. 

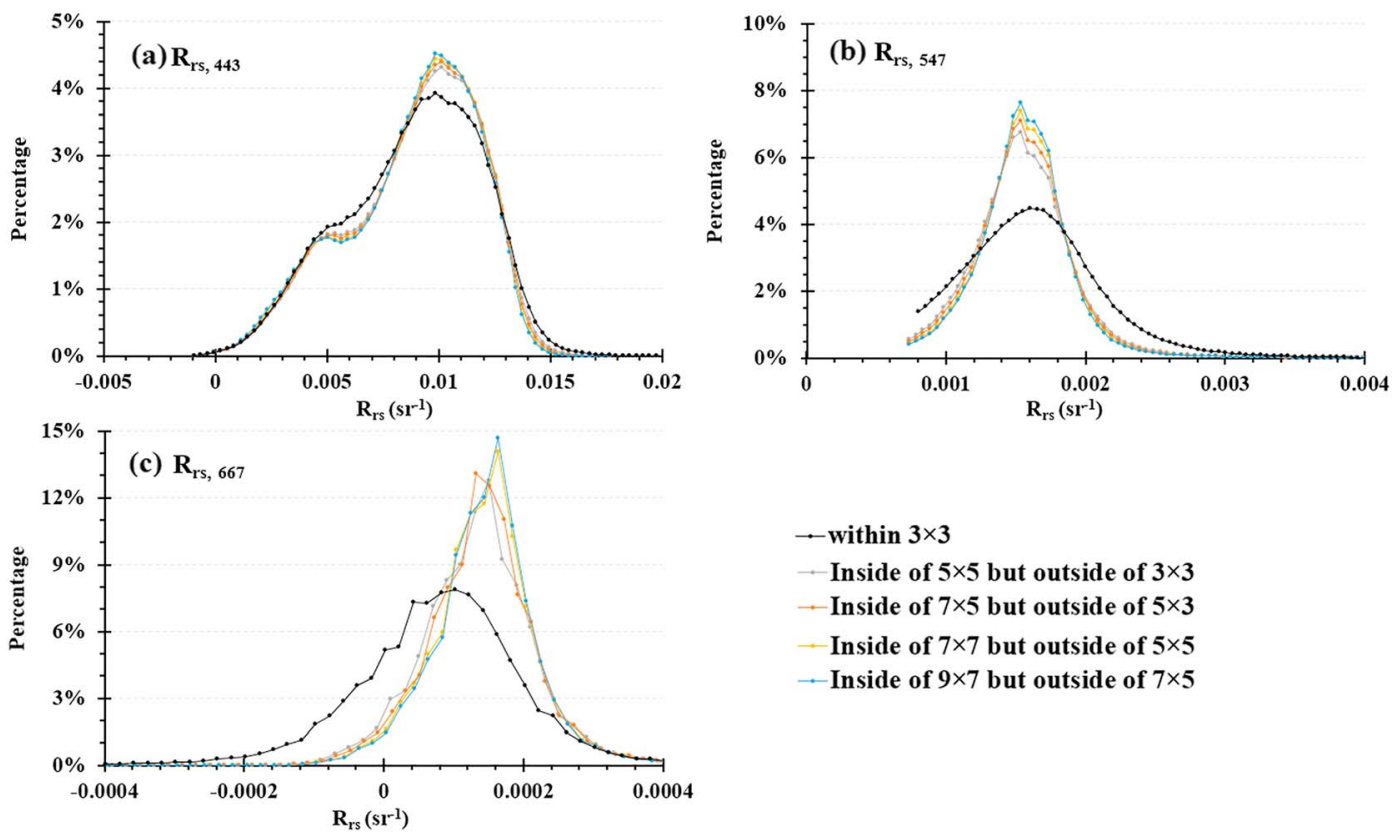

$\rightarrow$ within $3 \times 3$

$\rightarrow$ Inside of $5 \times 5$ but outside of $3 \times 3$

$\rightarrow$ Inside of $7 \times 5$ but outside of $5 \times 3$

- Inside of $7 \times 7$ but outside of $5 \times 5$

$\rightarrow$ Inside of $9 \times 7$ but outside of $7 \times 5$

Figure 10. Histograms of (a) $R_{r s, 443}$, (b) $R_{r s, 547}$, and (c) $R_{r s, 667}$ from pixels near cloud edges after applying different masking methods. The statistics were derived from 665 MODISA images in 2010 over the North Atlantic gyre $\left(60^{\circ}-40^{\circ} \mathrm{W}\right.$, $\left.15^{\circ}-35^{\circ} \mathrm{N}\right)$

measurements from ocean gyres are more trustable than others, leading to no difference in the statistical regressions. Therefore, more high-quality $\mathrm{Chl}$ and $\mathrm{R}_{\mathrm{rs}}(\lambda)$ data need to be collected from ocean gyres, especially from waters with $\mathrm{Chl}<0.05$ (or even $<0.03 \mathrm{mg} \mathrm{m}^{-3}$ ), in order to determine the lower bound of $\mathrm{Chl}$ in algorithm development. Currently, given the data scarcity and the slight difference between OCI1 and OCI2 for extremely clear waters, it is difficult to tell which algorithm is closer to the truth for these waters and what is the lowest possible $\mathrm{Chl}$ in global natural waters. However, some indirect inference
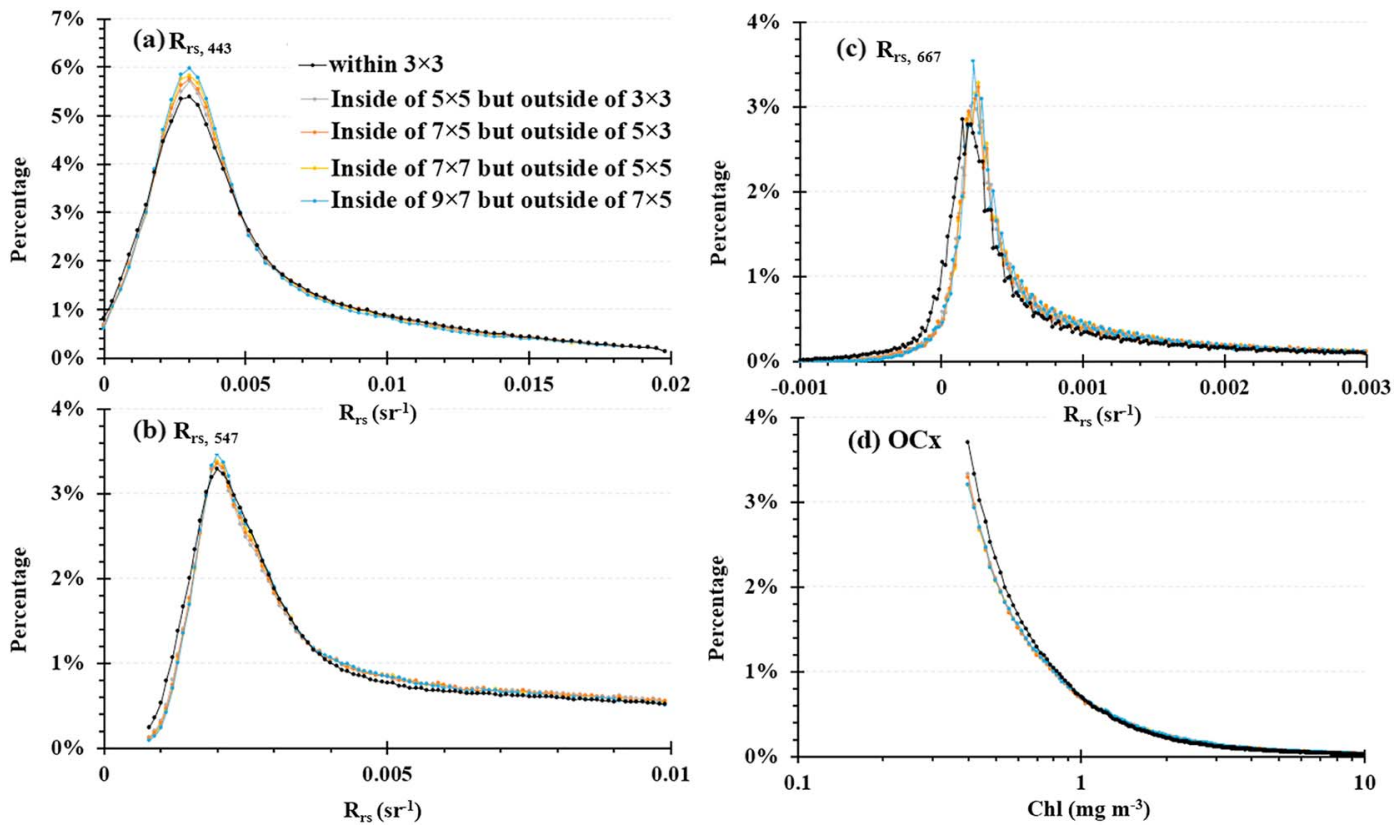

Figure 11. Histograms of (a) $\mathrm{R}_{\mathrm{rs}, 443}$, (b) $\mathrm{R}_{\mathrm{rs}, 547}$, (c) $\mathrm{R}_{\mathrm{rs}, 667}$, and (d) Chl $\mathrm{OCCx}_{\mathrm{x}}$ from pixels near cloud edges after applying different masking methods. The statistics were derived from all MODISA images in 2010 over the Gulf of Mexico $\left(98^{\circ}-80^{\circ} \mathrm{W}, 18^{\circ}-31^{\circ} \mathrm{N}\right)$ for $\mathrm{Chl}>0.4 \mathrm{mg} \mathrm{m}^{-3}$. 

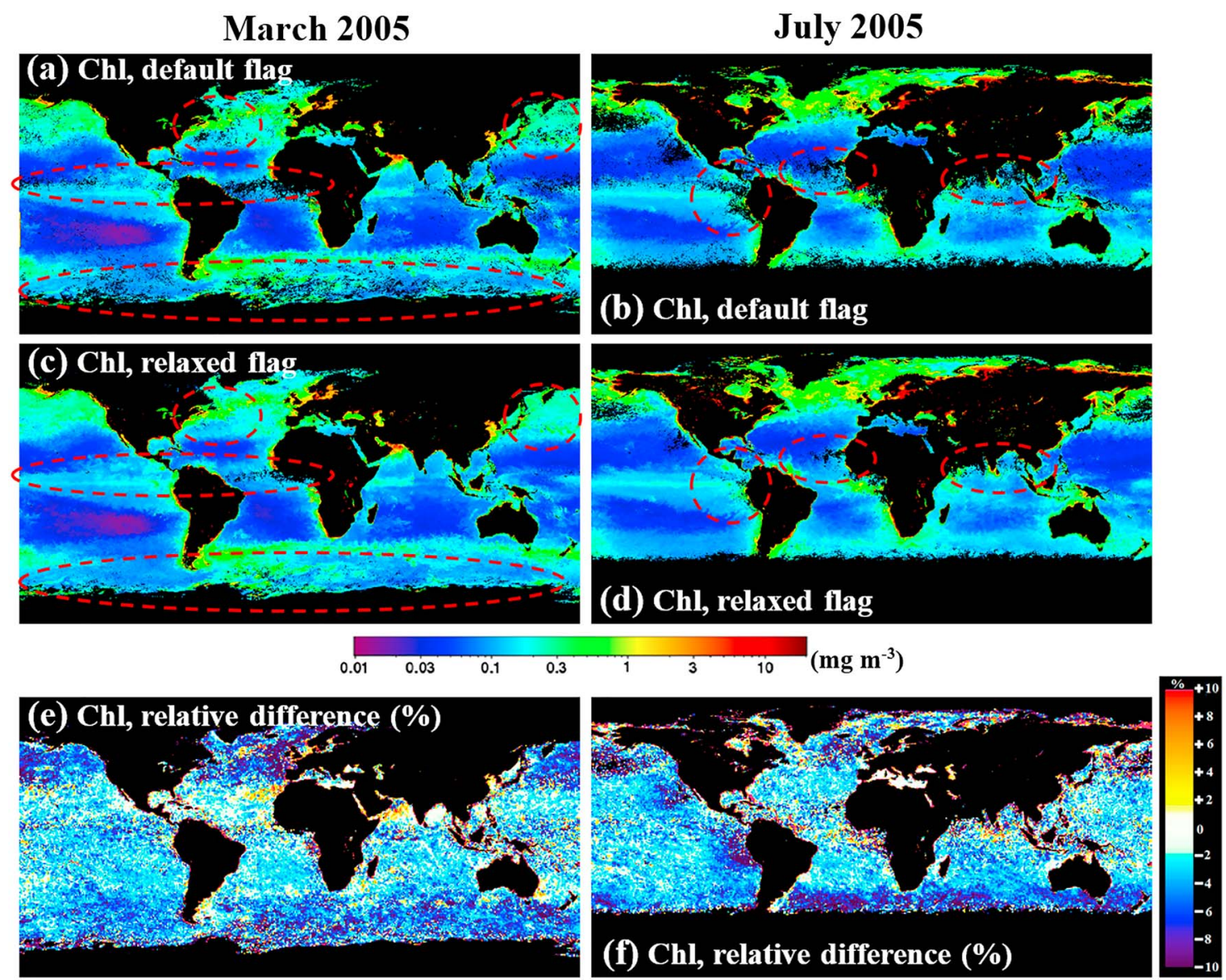

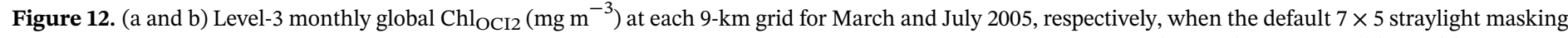
scheme was applied together with other quality controls to the individual level-2 files to derive the global composites. (c and d) Same as in (a) and (b) but relaxed straylight masking $(3 \times 3)$ was applied together with other quality controls. The red eclipses highlight regions where considerable amount of missing data from the former have been recovered in the latter. (e and f) Their relative (\%) differences (relaxed/default -1.0) are shown, respectively. To remove pepper noise, the images were spatially binned before calculating the difference, leading to the apparently reduced data gaps than shown in the default-flag maps.

suggests that $0.01 \mathrm{mg} \mathrm{m}^{-3}$ might be more reasonable than $0.02 \mathrm{mg} \mathrm{m}^{-3}$. For example, the maximum Secchi depth measured in the South Pacific gyre was $70 \mathrm{~m}$ (Doron et al., 2011). Using the "Case-1" bio-optical model (Morel \& Maritorena, 2001) and the new Secchi depth theory (Lee et al., 2015), this value more likely corresponds to $\mathrm{Chl}$ value of $\sim 0.01 \mathrm{mg} \mathrm{m}^{-3}$ rather than $0.02 \mathrm{mg} \mathrm{m}^{-3}$. However, without more field measurements of high-quality $\mathrm{Chl}$, this can only be used as indirect evidence to support OCI2. Indeed, the lowest $\mathrm{Chl}$ value in the algorithm development data set (NOMAD) is $0.012 \mathrm{mg} \mathrm{m}^{-3}$, indicating the need of more data around this value.

On the other hand, even without resolving the puzzle of which one is closer to the truth for low-Chl waters, OCI1 or OCI2, they both can be used to study changes induced by climate variability. This is because each algorithm is self-consistent, therefore even if the absolute Chl value may be slightly off the changes detected by the algorithm are still trustable. In this regard, algorithm consistency is more important than algorithm accuracy. This is exactly why the improved cross-sensor consistency from either OCI1 or OCI2 (over OCx) is important in order to form a seamless, multisensor climate data record, which can then be used to assess long-term ocean changes in response to climate variability (e.g., Antoine et al., 2005; Gregg et al., 2005; Polovina et al., 2008; Signorini et al., 2015).

\subsection{Data Quality, Quantity, and Uncertainty}

In addition to Chl algorithm refinement, this work also proposed a practical scheme to recover some of the previously masked cloud-free data through relaxing the cloud-adjacent straylight mask. Although these data exist at level-2, they are discarded in global level-3 composites using a $7 \times 5$ mask. Our results showed that 
March 2005
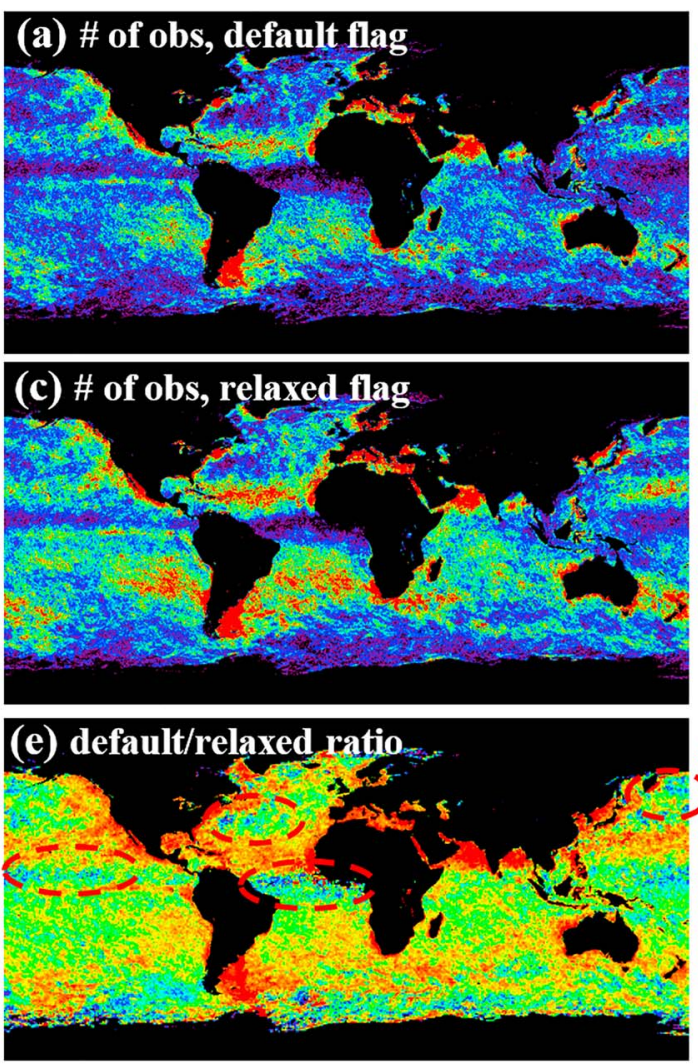
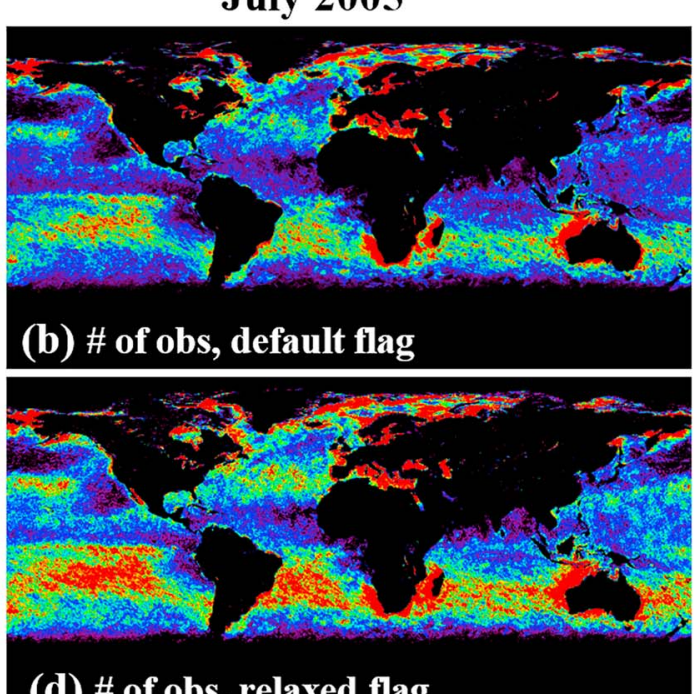

(d) \# of obs, relaxed flag

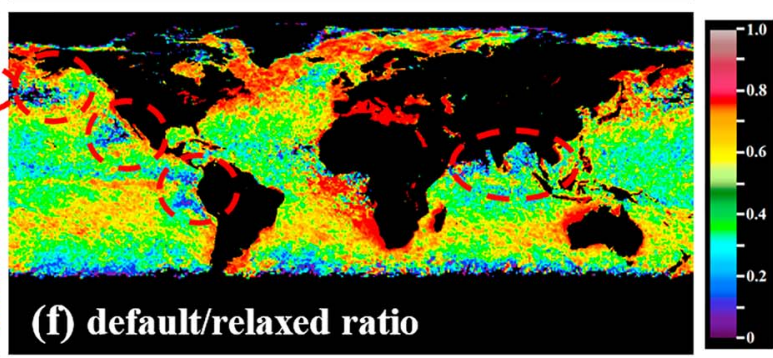

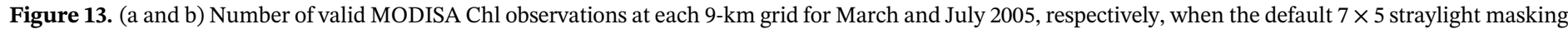
scheme was applied together with other quality controls to the individual level-2 files to derive the global composites. A number of 200 indicates that

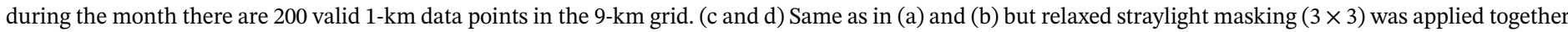

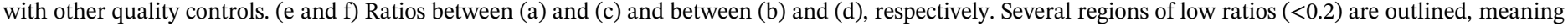
that the relative increase in valid observations can reach $>400 \%$ if the relaxed masking scheme is used. Overall the global average increase is about $40 \%$.

such a mask was probably too conservative, and a reduction to a $3 \times 3$ mask would recover many pixels with similar quality to those nearby pixels. Globally, these recovered pixels represent about $40 \%$ of the previous valid retrievals, thus indicating a significant increase in data quantity. In some regions during certain seasons, the increases could reach several hundred percent.

Such increases have profound impacts on both data availability at daily scale and data product uncertainties at longer (e.g., weekly, monthly, seasonal) scales. First, most global or regional studies have used monthly mean products to study spatial/temporal changes. Because product uncertainties induced by independent and normally distributed errors are inversely proportional to square root of number of observations, the increased number of valid retrievals will lead to reduced data product uncertainties. This type of uncertainty reduction has been demonstrated in Qi et al. (2017) using global ocean color data products. For a 39\% increase, uncertainties will be reduced by $15 \%(=1-1 / \operatorname{sqrt}(1.39))$. For some regions, the reduction can be much higher. For regions with significant and persistent cloud cover (e.g., Intertropical Convergence Zone, North Indian Ocean during summer), the new masking scheme may fill some of the monthly data gaps (i.e., from 0 observation to at least 1 observation) to lead to more spatially coherent patterns. For the same reason, when applied to level-2 files or short-term (three-day, seven-day) image composites, the new scheme would provide more spatial coverage to guide field measurements in near real time.

The increases from the new masking scheme are in relative terms. Overall the number of valid retrievals is very low ( $\sim$ \% for both MODISA and MODIST; Feng \& Hu, 2016a). After a 39\% increase this becomes $~ 7 \%$. Clearly, future studies should focus on whether there is additional room for further increases of data quantity without losing quality, for example, through relaxing the Sun glint masking threshold, through new 

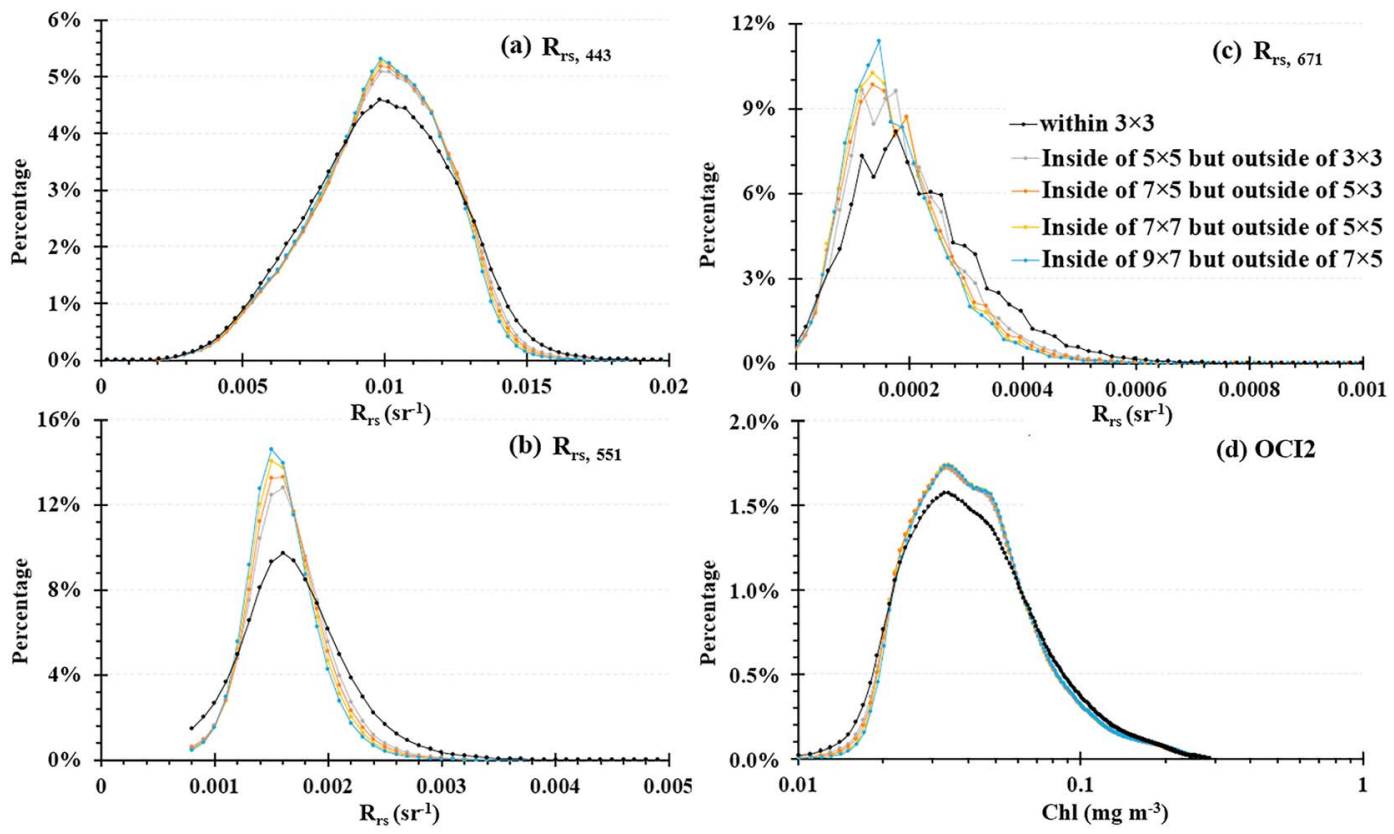

Figure 14. Histograms of (a) $R_{\mathrm{rs}, 443}$, (b) $\mathrm{R}_{\mathrm{rs}, 551}$, (c) $\mathrm{R}_{\mathrm{rs}, 671}$, and (d) $\mathrm{Ch} \mathrm{O}_{\mathrm{OCI} 2}$ from pixels near cloud edges after applying different masking methods. The statistics were derived from all VIIRS images in 2013 over the North Atlantic gyre for $\mathrm{Chl}<0.25 \mathrm{mg} \mathrm{m}^{-3}$.

algorithms to define straylight pixels (e.g., Jiang \& Wang, 2013), or through machine learning using the spectra of low-quality pixels (e.g., Chen et al., 2019).

Although the focus of this paper is on Chl data products, statistics of cloud-adjacent pixels showed that the $7 \times 5$ straylight mask might be relaxed to $3 \times 3$ even for $R_{r s}(\lambda)$. An extensive evaluation for the entire
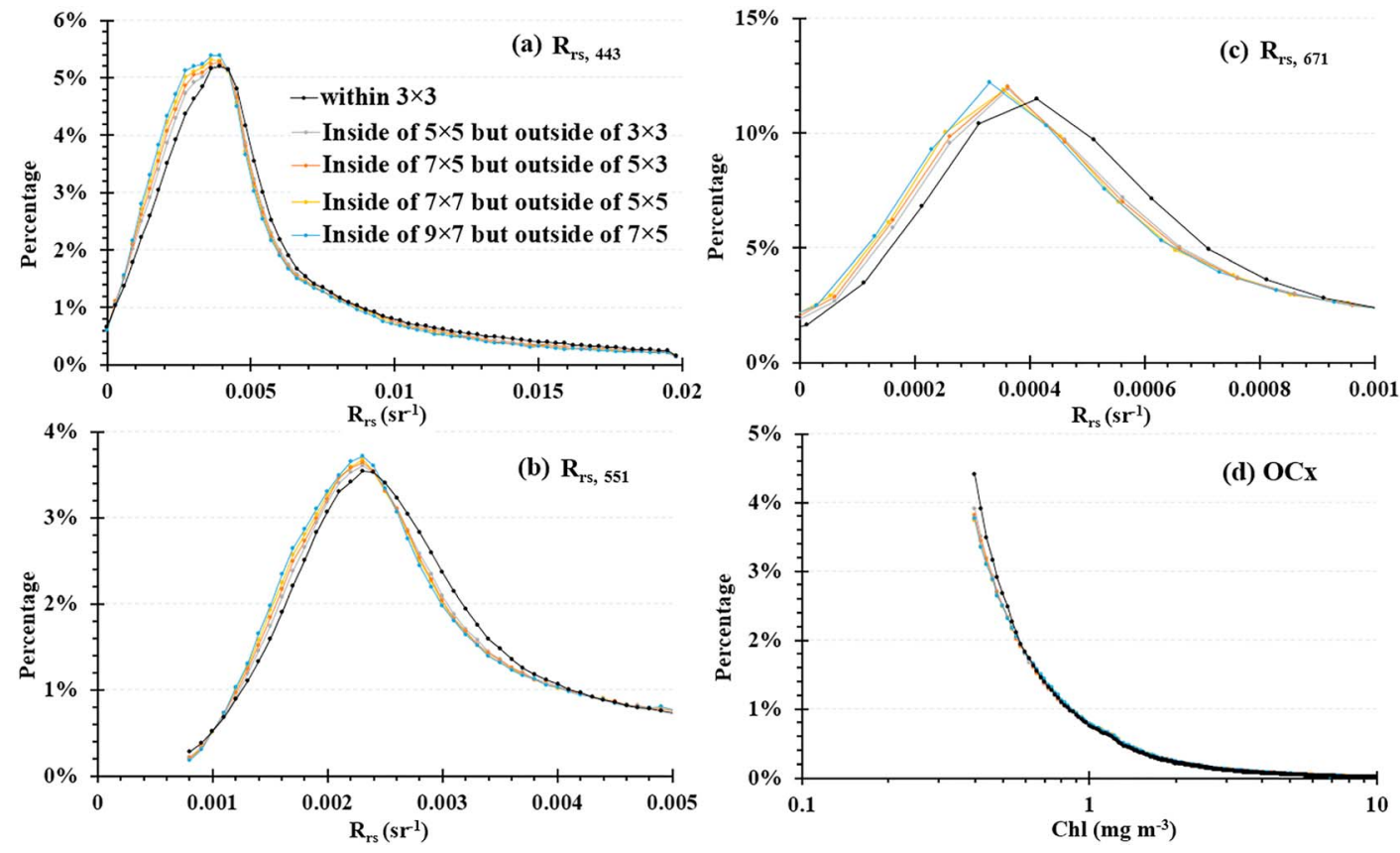

Figure 15. Histograms of (a) $R_{r s, 443}$, (b) $R_{r s, 551}$, (c) $R_{r s, 671}$, and (d) Chl $l_{\mathrm{OCx}}$ from pixels near cloud edges after applying different masking methods. The statistics were derived from all VIIRS images in 2013 over the Gulf of Mexico $\left(98^{\circ}-80^{\circ} \mathrm{W}, 18^{\circ}-31^{\circ} \mathrm{N}\right)$ for $\mathrm{Chl}>0.4 \mathrm{mg} \mathrm{m}^{-3}$. 
MODISA time series of 2003-2016 indicated that although the new masking scheme resulted in slightly different (up to $3 \%$ ) global statistics in $\mathrm{R}_{\mathrm{rs}}(667)$, the global statistics of $\mathrm{R}_{\mathrm{rs}}(\lambda)$ for all MODISA ocean bands remained nearly unchanged (https://oceancolor.gsfc.nasa.gov/analysis/global/at140_at135/; AT135 $=7 \times 5$ masking, AT140 $=3 \times 3$ masking). However, the distributions of regional $\mathrm{R}_{\mathrm{rs}}(\lambda)$ have changed due to increased number of observations (e.g., Figures 12 and 13). This has significant implications for all other ocean color data products (e.g., inherent optical properties such as absorption and backscattering coefficients), as $\mathrm{R}_{\mathrm{rs}}(\lambda)$ is the common input to algorithms for these products. Therefore, similar analyses may be conducted on these products in the future. Likewise, whether the new straylight masking scheme is applicable to sensors other than MODISA should also be evaluated. For example, analyses of VIIRS data over the North Atlantic gyre and Gulf of Mexico for both clear waters $(\mathrm{Chl}<0.25)$ and more productive waters $\left(\mathrm{Chl}>0.4 \mathrm{mg} \mathrm{m}^{-3}\right)$, respectively, showed that statistically, there is little difference between pixels within the $3 \times 3-7 \times 5$ rings and outside the $7 \times 5$ straylight mask (Figures 14 and 15). These results indicate that VIIRS straylight mask may also be relaxed from $7 \times 5$ to $3 \times 3$ in order to increase data quantity without compromising data quality.

Unlike other data recovering schemes that rely on a model to change the $\mathrm{R}_{\mathrm{rs}}(\lambda)$ values in order to improve coverage (Chen et al., 2016) or a machine learning approach to use $\mathrm{R}_{\mathrm{rc}}(\lambda$; Rayleigh corrected reflectance) to improve coverage (Chen et al., 2019), the new masking scheme does not change $\mathrm{R}_{\mathrm{rs}}(\lambda)$, therefore is straightforward to implement and test for $\mathrm{Chl}$ retrievals. Once proven feasible, the scheme is expected to have a major impact on ocean color data records from either a single sensor or merged multiple sensors, for example, by the Ocean Color Climate Change Initiative supported by the European Space Agency (Brewin et al., 2015) or by a NASA-funded multisensor data merging effort (Maritorena et al., 2010).

Finally, regardless of all its advantages, the CI design is still empirical, and uncertainties due to variable contributions from colored dissolved organic matter or other nonliving water constituents are embedded in the empirical Chl data products, and such contributions may vary across different ocean basins (Szeto et al., 2011; Figure 5 of $\mathrm{Hu}$ et al., 2013). Although the impact of such uncertainties may be small when evaluating relative long-term $\mathrm{Chl}$ changes of individual ocean basins, they may represent a small but variable bias in the absolute $\mathrm{Chl}$ values across ocean basins. Such uncertainties might be reduced through an empirical correction scheme using the curvature from the 412-, 443-, and 488-nm bands (e.g., Hu et al., 2014), yet its efficiency still remains to be tested.

\section{Conclusion}

The original OCI algorithm designed to retrieve Chl of global ocean surface waters from satellite ocean color measurements has been revisited using more field data. Compared to the original OCI algorithm (OCI1), the new OCI2 algorithm shows similar improvements over the traditional OCx for oligotrophic waters in terms of accuracy, image quality, and cross-sensor consistency between SeaWiFS, MODISA, and VIIRS, but at the same time leads to smoother transition in the intermediate Chl range $\left(0.25-0.4 \mathrm{mg} \mathrm{m}^{-3}\right)$. Therefore, OCI2 may be a better choice than OCI1 for global data processing. More importantly, a relaxed straylight masking scheme (from $7 \times 5$ to $3 \times 3$ pixels) leads to significantly increased data quantity without losing data quality for both Chl and $\mathrm{R}_{\mathrm{rs}}(\lambda)$ when tested with MODISA and VIIRS over the North Atlantic (oligotrophic waters) and Gulf of Mexico (more productive waters). The increases in data quantity over global oceans reach $39 \%$.

Acknowledgments

This study was supported by the U.S. NASA (NNX14AM63G, NNX15AB13A NNX13AO53G) for MODIS and VIIRS algorithm refinement and for data product improvement. Satellite data were provided by NASA Ocean Biology Processing Group (OBPG) while VIIRS level-1 data were provided by NOAA. We thank all researchers who contributed to the NASA SeaBASS data archive. All field and satellite data can be obtained from the NASA OB.DAAC through http://oceancolor.gsfc.nasa. gov. We thank the two anonymous reviewers for their valuable comments to improve this manuscript.
Future efforts should focus on collection of high-quality data in ocean gyres with $\mathrm{Chl}<0.05 \mathrm{mg}^{-3}$ in order to further improve data product accuracy for these extremely clear waters, and focus on evaluation of other ocean color data products near cloud edges from the mainstream ocean color sensors.

\section{References}

Antoine, D., Morel, A., Gordon, H. R., Banzon, V. F., \& Evans, R. H. (2005). Bridging ocean color observations of the 1980s and 2000s in search of long-term trends. Journal of Geophysical Research, 110, C06009. https://doi.org/10.1029/2004JC002620

Bailey, S. W., \& Werdell, P. J. (2006). A multi-sensor approach for the on-orbit validation of ocean color satellite data products. Remote Sensing of Environment, 102(1-2), 12-23. https://doi.org/10.1016/j.rse.2006.01.015

Brewin, R. J. W., Raitsos, D. E., Pradhan, Y., \& Hoteit, I. (2013). Comparison of chlorophyll in the Red Sea derived from MODIS-aqua and in vivo fluorescence. Remote Sensing of Environment, 136, 218-224. https://doi.org/10.1016/j.rse.2013.04.018

Brewin, R. J. W., Sathyendranath, S., Müller, D., Brockmann, C., Deschamps, P. Y., Devred, E., et al. (2015). The ocean colour climate change initiative: III. A round-robin comparison on in-water biooptical algorithms. Remote Sensing of Environment, 162, $271-294$. https://doi.org/10.1016/j.rse.2013.09.016 
Campbell, J. W. (1995). The lognormal distribution as a model for bio-optical variability in the sea. Journal of Geophysical Research, 100(C7), 13,237-13,254. https://doi.org/10.1029/95JC00458

Carder, K. L., Chen, F. R., Lee, Z. P., Hawes, S. K., \& Kamykowski, D. (1999). Semianalytic moderate-resolution imaging spectrometer algorithms for chlorophyll $a$ and absorption with bio-optical domains based on nitrate-depletion temperatures. Journal of Geophysical Research, 104(C3), 5403-5421. https://doi.org/10.1029/1998JC900082

Chen, J., Lee, Z., Hu, C., \& Wei, J. (2016). Improving satellite data products for open oceans with a scheme to correct the residual errors in remote sensing reflectance. Journal of Geophysical Research: Oceans, 121, 3866-3886. https://doi.org/10.1002/2016JC011673

Chen, S., Hu, C., Barnes, B. B., Xie, Y., Lin, G., \& Qiu, Z. (2019). Improving ocean color data coverage through machine learning. Remote Sens. Environ., Remote Sens. Environ., 222, 286-302. https://doi.org/10.1016/j.rse.2018.12.023

Dierssen, H. M. (2010). Perspectives on empirical approaches for ocean color remote sensing of chlorophyll in a changing climate. Proceedings of the National Academy of Sciences, 107(40), 17,073-17,078. https://doi.org/10.1073/pnas.0913800107

Doron, M., Babin, M., Hembise, O., Mangin, A., \& Garnesson, P. (2011). Ocean transparency from space: Validation of algorithms using MERIS, MODIS and SeaWiFS data. Remote Sensing of Environment, 115(12), 2986-3001. https://doi.org/10.1016/j.rse.2011.05.019

Feng, L., \& Hu, C. (2016a). Comparison of valid ocean observations between MODIS Terra and Aqua over the global oceans. IEEE Transactions on Geoscience and Remote Sensing, 54(3), 1575-1585. https://doi.org/10.1109/TGRS.2015.2483500

Feng, L., \& Hu, C. (2016b). Cloud adjacency effects on top-of-atmosphere radiance and ocean color data products: A statistical assessment Remote Sensing of Environment, 174, 301-313. https://doi.org/10.1016/j.rse.2015.12.020

Franz, B. A. (2014). NASA Ocean Biology Processing Group update (MODIS, VIIRS, MERIS, HICO, GOCI, SGLI, OLCI, LandSat-8, MultiMission Processing). NASA Ocean Color Research Team Meeting, 5-7 May 2014. Washington, DC. Retrieved from https://oceancolor. gsfc.nasa.gov/meetings/scienceteam/ocrt/may2014/140505/Bontempi_OCRT_2014_NASA_Update.pdf

Franz, B. A., Bailey, S. W., Werdell, P. J., \& McClain, C. R. (2007). Sensor-independent approach to the vicarious calibration of satellite ocean color radiometry. Applied Optics, 46(22), 5068-5082. https://doi.org/10.1364/A0.46.005068

Franz, B. A., Behrenfeld, M. J., Siegel, D. A., \& Signorini, S. R. (2016). Global ocean phytoplankton [in "state of the climate in 2015"]. Bulletin of the American Meteorological Society, 97(8), Si-S275. https://doi.org/10.1175/2016BAMSStateoftheClimate.1

Franz, B. A., Werdell, P. J., Meister, G., Bailey, S. W., Eplee, R. E., Feldman, G. C., et al. (2005). The continuity of ocean color measurements from SeaWiFS to MODIS. Proc. SPIE 5882, Earth Observing Systems X, 58820W (2005/08/22). https://doi.org/10.1117/ 12.620069

Frouin, R., Schwindling, M., \& Deschamps, P.-Y. (1996). Spectral reflectance of sea foam in the visible and near-infrared: In situ measurements and remote sensing implications. Journal of Geophysical Research, 101(C6), 14,361-14,371. https://doi.org/10.1029/ 96JC00629

Gordon, H. R. (1997). Atmospheric correction of ocean color imagery in the Earth Observing System era. Journal of Geophysical Research, 102(D14), 17,081-17,106. https://doi.org/10.1029/96JD02443

Gordon, H. R., \& Clark, D. K. (1981). Clear water radiances for atmospheric correction of coastal zone color scanner imagery. Applied Optics, 20(24), 4175-4180. https://doi.org/10.1364/AO.20.004175

Gordon, H. R., \& Wang, M. (1994). Retrieval of water-leaving radiance and aerosol optical thickness over the oceans with SeaWiFS: A preliminary algorithm. Applied Optics, 33(3), 443-452. https://doi.org/10.1364/AO.33.000443

Gregg, W. W., Casey, N. W., \& McClain, C. R. (2005). Recent trends in global ocean chlorophyll. Geophysical Research Letters, 32 , L03606. https://doi.org/10.1029/2004GL021808

Hu, C., \& Campbell, J. (2014). Oceanic chlorophyll-a content. In J. M. Hanes (Ed.), Biophysical Applications of Satellite Remote Sensing (pp. 171-203). Berlin Heidelberg: Springer Remote Sensing/Photogrammetry. Springer-Verlag. https://doi.org/10.1007/978-3-64225047-7_7

Hu, C., Feng, L., \& Lee, Z. (2013). Uncertainties of SeaWiFS and MODIS remote sensing reflectance: Implications from clear water measurements. Remote Sensing of Environment, 133, 168-182. https://doi.org/10.1016/j.rse.2013.02.012

Hu, C., Lee, Z., \& Franz, B. (2012). Chlorophyll $a$ algorithms for oligotrophic oceans: A novel approach based on three-band reflectance difference. Journal of Geophysical Research, 117, C01011. https://doi.org/10.1029/2011JC007395

Hu, C., Qi, L., Lee, Z., \& Franz, B. A. (2014). Minimize CDOM impact on the band-subtraction chlorophyll algorithm through optical weighting: Preliminary results. Ocean Optics XXII, Oct 24-31, 2014, Portland, ME.

IOCCG (2006). Remote sensing of inherent optical properties: Fundamentals, tests of algorithms, and applications. Reports of the International Ocean-Colour Coordinating Group, No. 5. Z.-P. Lee. Dartmouth, Canada, IOCCG.

Jiang, L., \& Wang, M. (2013). Identification of pixels with stray light and cloud shadow contaminations in the satellite ocean color data processing. Applied Optics, 52, 6757-6770.

Kahru, M., \& Mitchell, B. G. (1999). Empirical chlorophyll algorithm and preliminary SeaWiFS validation for the California Current. International Journal of Remote Sensing, 20(17), 3423-3429. https://doi.org/10.1080/014311699211453

King, M. D., Platnick, S., Menzel, W. P., Ackerman, S. A., \& Hubanks, P. A. (2013). Spatial and temporal distribution of clouds observed by MODIS onboard the Terra and Aqua satellites. IEEE Transactions on Geoscience and Remote Sensing, 51(7), 3826-3852. https://doi.org/ 10.1109/TGRS.2012.2227333

Le, C., Zhou, X., Hu, C., Lee, Z., Li, L., \& Stramski, D. (2018). A color-index-based empirical algorithm for determining particulate organic carbon concentration in the ocean from satellite observations. Journal of Geophysical Research: Oceans, 123, 7407-7419. https://doi.org/ 10.1029/2018JC014014

Lee, Z. P., Carder, K. L., \& Arnone, R. (2002). Deriving inherent optical properties from water color: A multi-band quasi-analytical algorithm for optically deep waters. Applied Optics, 41(27), 5755-5772. https://doi.org/10.1364/AO.41.005755

Lee, Z. P., Shang, S., Hu, C., Du, K., Weidemann, A., Hou, W., et al. (2015). Secchi disk depth: A new theory and mechanistic model for underwater visibility. Remote Sensing of Environment, 169, 139-149. https://doi.org/10.1016/j.rse.2015.08.002

Maritorena, S., d'Andon, O. H. F., Mangin, A., \& Siegel, D. A. (2010). Merged satellite ocean color data products using a bio-optical model: Characteristics, benefits and issues. Remote Sensing of Environment, 114(8), 1791-1804. https://doi.org/10.1016/j. rse.2010.04.002

Maritorena, S., Siegel, D. A., \& Peterson, A. (2002). Optimization of a semi-analytical ocean color model for global scale applications. Applied Optics, 41(15), 2705-2714. https://doi.org/10.1364/AO.41.002705

McClain, C. R. (2009). A decade of satellite ocean color observations. Annual Review of Marine Science, 1(1), 19-42. https://doi.org/10.1146/ annurev.marine.010908.163650

McClain, C. R., Feldman, G. C., \& Hooker, S. B. (2004). An overview of the SeaWiFS project and strategies for producing a climate research quality global ocean bio-optical time series. Deep-Sea Research II, 51(1-3), 5-42. https://doi.org/10.1016/j.dsr2.2003.11.001 
Meister, G., \& McClain, C. R. (2010). Point-spread function of the ocean color bands of the Moderate Resolution Imaging Spectroradiometer on Aqua. Applied Optics, 49(32), 6276-6285. https://doi.org/10.1364/AO.49.006276

Mitchell, C., Hu, C., Bowler, B., Drapeau, D., \& Balch, W. M. (2017). Estimating particulate inorganic carbon concentrations of the global ocean from ocean color measurements using a reflectance difference approach. Journal of Geophysical Research: Oceans, 122, 8707-8720. https://doi.org/10.1002/2017JC013146

Moore, T. S., Campbell, J. W., \& Feng, H. (2015). Characterizing the uncertainties in spectral remote sensing reflectance for SeaWiFS and MODIS-Aqua based on global in situ matchup data sets. Remote Sensing of Environment, 159, 14-27. https://doi.org/10.1016/j. rse.2014.11.025

Morel, A., \& Maritorena, S. (2001). Bio-optical properties of oceanic waters: A reappraisal. Journal of Geophysical Research, 106(C4), 7163-7180. https://doi.org/10.1029/2000JC000319

O'Reilly, J. E., Maritorena, S., O'brien, M. C., Siegel, D. A., Toole, D., Menzies, D., et al. (2000). SeaWiFS Postlaunch calibration and validation analyses, Part 3. In S. B. Hooker \& E. R. Firestone (Eds.), NASA Tech. Memo. 2000-206892 (Vol. 11, 49 pp.). Greenbelt, MD: NASA Goddard Space Flight Center.

Polovina, J. J., Howell, E. A., \& Abecassis, M. (2008). Ocean's least productive waters are expanding. Geophysical Research Letters, 35, L03618. https://doi.org/10.1029/2007GL031745

Qi, L., Lee, Z., Hu, C., \& Wang, M. (2017). Requirement of minimal signal-to-noise ratios of ocean color sensors and uncertainties of ocean color products. Journal of Geophysical Research: Oceans, 122, 2595-2611. https://doi.org/10.1002/2016JC012558

Sathyendranath, S., Prieur, L., \& More, A. (1989). A three component model of ocean colour and its application to remote sensing of phytoplankton pigments in coastal waters. International Journal of Remote Sensing, 10(8), 1373-1394. https://doi.org/10.1080/ 01431168908903974

Signorini, S., Franz, B. A., \& McClain, C. R. (2015). Chlorophyll variability in the oligotrophic gyres: Mechanisms, seasonality and trends. Frontiers in Marine Science, 2. https://doi.org/10.3389/fmars.2015.00001

Stumpf, R. P., Arnone, R., Gould, R. W., Martinolich, P. M., \& Ransibrahmanakul, V. (2003). A Partially-Coupled Ocean-Atmosphere Model for Retrieval of Water-Leaving Radiance From SeaWiFS in Coastal Waters (Vol. 22). Maryland: NASA Goddard Space Flight Center, Greenbelt.

Szeto, M., Werdell, P. J., Moore, T. S., \& Campbell, J. W. (2011). Are the world's oceans optically different? Journal of Geophysical Research, 116, C00H04. https://doi.org/10.1029/2011JC007230

Wang, M., \& Bailey, S. W. (2001). Correction of Sun glint contamination on the SeaWiFS ocean and atmosphere products. Applied Optics, 40(27), 4790-4798. https://doi.org/10.1364/AO.40.004790

Wang, M., \& Shi, W. (2007). The NIR-SWIR combined atmospheric correction approach for MODIS ocean color data processing. Optics Express, 15(24), 15,722-15,733. https://doi.org/10.1364/OE.15.015722

Wang, M., \& Son, S.-H. (2016). VIIRS-derived chlorophyll- $a$ using the ocean color index method. Remote Sensing of Environment, 182, 141-149. https://doi.org/10.1016/j.rse.2016.05.001

Wei, J., Lee, Z., \& Shang, S. (2016). A system to measure the data quality of spectral remote sensing reflectance of aquatic environments Journal of Geophysical Research: Oceans, 121, 8189-8207. https://doi.org/10.1002/2016JC012126

Werdell, P. J., \& Bailey, S. W. (2005). An improved in-situ bio-optical data set for ocean color algorithm development and satellite data product validation. Remote Sensing of Environment, 98(1), 122-140. https://doi.org/10.1016/j.rse.2005.07.001

Werdell, P. J., Bailey, S. W., Fargion, G., Pietras, C., Knobelspiesse, K., Feldman, G. C., \& McClain, C. R. (2003). Unique data repository facilitates ocean color satellite validation. Eos, Transactions of the American Geophysical Union, 84(38), 377. https://doi.org/10.1029/ 2003EO380001 